TITLE:

\title{
Distribution of Fos-immunoreactive cells in rat forebrain and midbrain following social defeat stress and diazepam treatment.
}

\section{$\operatorname{AUTHOR}(\mathrm{S}):$}

Lkhagvasuren, B; Oka, T; Nakamura, Y; Hayashi, H; Sudo, N; Nakamura, K

\section{CITATION:}

Lkhagvasuren, B ... [et al]. Distribution of Fos-immunoreactive cells in rat forebrain and midbrain following social defeat stress and diazepam treatment.. Neuroscience 2014, 272 : 34-57

\section{ISSUE DATE:}

2014-07-11

URL:

http://hdl.handle.net/2433/187801

\section{RIGHT:}

(C) 2014 IBRO. Published by Elsevier Ltd.; この論文は出版社版でありま せん。引用の際には出版社版をご確認じ利用ください。; This is not the published version. Please cite only the published version. 


\title{
DISTRIBUTION OF FOS-IMMUNOREACTIVE CELLS IN RAT FOREBRAIN AND MIDBRAIN FOLLOWING SOCIAL DEFEAT STRESS AND DIAZEPAM TREATMENT
}

\author{
B. LKHAGVASUREN, ${ }^{a}$ T. OKA, ${ }^{a}$ Y. NAKAMURA, ${ }^{b}$ H. HAYASHI, ${ }^{c}$ \\ N. SUDO ${ }^{a}$ and K. NAKAMURA ${ }^{\mathrm{b}, \mathrm{d}^{*}}$
}

a Department of Psychosomatic Medicine, Graduate School of Medical Sciences, Kyushu University, 3-1-1 Maidashi, Higashi-ku, Fukuoka 812-8582, Japan

${ }^{\mathrm{b}}$ Career-Path Promotion Unit for Young Life Scientists, Kyoto University, YoshidaKonoe-cho, Sakyo-ku, Kyoto 606-8501, Japan

${ }^{c}$ Division of Psychosomatic Medicine, Department of Neurology, University of Occupational and Environmental Health, 1-1, Iseigaoka, Yahata-Nishi-ku, Kitakyushu, Fukuoka 807-8555, Japan

${ }^{d}$ Precursory Research for Embryonic Science and Technology (PRESTO), Japan Science and Technology Agency, 4-1-8, Honcho, Kawaguchi, Saitama 332-0012, Japan

${ }^{*}$ Corresponding author. Tel: +81-75-753-9308; fax: +81-75-753-9311.

E-mail address: kazu@cp.kyoto-u.ac.jp or nkazuhir@gmail.com (K. Nakamura).

Abbreviations: BAT, brown adipose tissue; BNST, bed nucleus of the stria terminalis; $\mathrm{IR}$, immunoreactive; PG, prostaglandin; $\mathrm{PSH}$, psychological stress-induced hyperthermia; $T_{\mathrm{c}}$, body core temperature. 


\section{Abstract}

The anxiolytic diazepam selectively inhibits psychological stress-induced autonomic and behavioral responses without causing noticeable suppression of other central performances. This pharmacological property of diazepam led us to the idea that neurons that exhibit diazepam-sensitive, psychological stress-induced activation are potentially those recruited for stress responses. To obtain neuroanatomical clues for the central stress circuitries, we examined the effects of diazepam on psychological stress-induced neuronal activation in broad brain regions. Rats were exposed to a social defeat stress, which caused an abrupt increase in body temperature by up to $2^{\circ} \mathrm{C}$. Pretreatment with diazepam $(4 \mathrm{mg} / \mathrm{kg}$, i.p.) attenuated the stress-induced hyperthermia, confirming an inhibitory physiological effect of diazepam on the autonomic stress response. Subsequently, the distribution of cells expressing Fos, a marker of neuronal activation, was examined in 113 forebrain and midbrain regions of these rats after the stress exposure and diazepam treatment. The stress following vehicle treatment markedly increased Fos-immunoreactive cells in most regions of the cerebral cortex, limbic system, thalamus, hypothalamus and midbrain, which included parts of the autonomic, neuroendocrine, emotional and arousal systems. The diazepam treatment significantly reduced the stress-induced Fos expression in many brain regions including the prefrontal, sensory and motor cortices, septum, medial amygdaloid nucleus, medial and lateral preoptic areas, parvicellular paraventricular hypothalamic nucleus, dorsomedial hypothalamus, perifornical nucleus, tuberomammillary nucleus, association, midline and intralaminar thalami, and median and dorsal raphe nuclei. In contrast, diazepam increased Fosimmunoreactive cells in the central amygdaloid nucleus, medial habenular nucleus, ventromedial hypothalamic nucleus and magnocellular lateral hypothalamus. These results provide important information for elucidating the neural circuitries that mediate the autonomic and behavioral responses to psychosocial stressors.

Key words: emotion, mapping, psychological stress-induced hyperthermia, psychogenic fever, psychosocial stress, stress circuit. 
Abbreviations in figures

\begin{tabular}{|c|c|}
\hline $3 \mathrm{~V}$ & Third ventricle \\
\hline ac & Anterior commissure \\
\hline ACo & Cortical amygdaloid nucleus \\
\hline $\mathrm{AH}$ & Anterior hypothalamic area \\
\hline $\mathrm{Aq}$ & Aqueduct \\
\hline Arc & Arcuate nucleus \\
\hline$B L$ & Basolateral amygdaloid nucleus \\
\hline BM & Basomedial amygdaloid nucleus \\
\hline CA1-CA3 & CA1-CA3 fields of Ammon's horn \\
\hline cc & Corpus callosum \\
\hline $\mathrm{cCe}$ & Caudal part of the central amygdaloid nucleus \\
\hline Cf & Cuneiform nucleus \\
\hline $\mathrm{cg}$ & Cingulum \\
\hline $\mathrm{Cg}$ & Cingulate cortex \\
\hline$C L$ & Central lateral thalamic nucleus \\
\hline $\mathrm{CM}$ & Central medial thalamic nucleus \\
\hline DG & Dentate gyrus \\
\hline $\mathrm{DH}$ & Dorsal hypothalamic area \\
\hline $\mathrm{DMH}$ & Dorsomedial hypothalamic nucleus \\
\hline DR & Dorsal raphe nucleus \\
\hline En & Endopiriform nucleus \\
\hline f & Fornix \\
\hline ic & Internal capsule \\
\hline IF & Interfascicular nucleus \\
\hline IL & Infralimbic cortex \\
\hline IMD & Intermediodorsal thalamic nucleus \\
\hline Ins & Insular cortex \\
\hline LD & Laterodorsal thalamic nucleus \\
\hline LHb & Lateral habenular nucleus \\
\hline lo & Lateral olfactory tract \\
\hline LPO & Lateral preoptic area \\
\hline LV & Lateral ventricle \\
\hline M & Motor cortex \\
\hline MCLH & Magnocellular nucleus of the lateral hypothalamus \\
\hline MD & Mediodorsal thalamic nucleus \\
\hline Me & Medial amygdaloid nucleus \\
\hline $\mathrm{MHb}$ & Medial habenular nucleus \\
\hline $\mathrm{ml}$ & Medial leminiscus \\
\hline mlf & Medial longitudinal fasciculus \\
\hline $\mathrm{MnPO}$ & Median preoptic nucleus \\
\hline MnR & Median raphe nucleus \\
\hline MPO & Medial preoptic area \\
\hline
\end{tabular}




\begin{tabular}{|c|c|}
\hline $\mathrm{mt}$ & Mammillothalamic tract \\
\hline och & Optic chiasm \\
\hline opt & Optic tract \\
\hline OVLT & Organum vasculosum lamina terminalis \\
\hline PAGd & Dorsal part of the periaqueductal gray \\
\hline PAGI & Lateral part of the periaqueductal gray \\
\hline PAGvl & Ventrolateral part of the periaqueductal gray \\
\hline PaLM & Lateral magnocellular part of the paraventricular hypothalamic nucleus \\
\hline PaMP & Medial parvicellular part of the paraventricular hypothalamic nucleus \\
\hline $\mathrm{PaV}$ & Ventral part of the paraventricular hypothalamic nucleus \\
\hline PC & Paracentral thalamic nucleus \\
\hline Pef & Perifornical nucleus \\
\hline $\mathrm{PH}$ & Posterior hypothalamic area \\
\hline Pir I-III & Layers I-III of the piriform cortex \\
\hline PLH & Peduncular part of the lateral hypothalamus \\
\hline PMd & Dorsal part of the premammillary nucleus \\
\hline PMv & Ventral part of the premammillary nucleus \\
\hline PN & Paranigral nucleus \\
\hline PrL & Prelimbic cortex \\
\hline PV & Paraventricular thalamic nucleus \\
\hline $\mathrm{R}$ & Red nucleus \\
\hline $\mathrm{Re}$ & Reuniens thalamic nucleus \\
\hline $\mathrm{Rh}$ & Rhomboid thalamic nucleus \\
\hline RLi & Rostral linear nucleus of the raphe \\
\hline S1 & Primary somatosensory cortex \\
\hline SCh & Suprachiasmatic nucleus \\
\hline SHy & Septohypothalamic nucleus \\
\hline sm & Stria medullaris thalamus \\
\hline SN & Substantia nigra \\
\hline SO & Supraoptic nucleus \\
\hline STd & Dorsal divisions of the bed nucleus of the stria terminalis \\
\hline STV & Ventral divisions of the bed nucleus of the stria terminalis \\
\hline Sub & Submedius thalamic nucleus \\
\hline VL & Ventrolateral thalamic nucleus \\
\hline VM & Ventral medial thalamic nucleus \\
\hline $\mathrm{VMH}$ & Ventromedial hypothalamic nucleus \\
\hline VS & Ventral subiculum \\
\hline VTA & Ventral tegmental area \\
\hline VTg & Ventral tegmental nucleus \\
\hline VTM & Ventral tuberomammillary nucleus \\
\hline $\mathrm{ZI}$ & Zona incerta \\
\hline
\end{tabular}




\section{INTRODUCTION}

Psychological stress induces a variety of autonomic, neuroendocrine and behavioral responses. The development of stress responses involves central neural processes to perceive and integrate stress signals as well as to output autonomic and somatic (behavioral) motor commands to cope with stressors. However, the brain circuitry mechanism underlying stress responses is poorly understood. With the recent introduction of optogenetics, it is now possible to manipulate activities of specific populations of neurons in vivo, which is a powerful approach for probing the central neural circuitries recruited for stress responses (Sparta et al., 2013). However, a prerequisite to those optogenetics strategies is to know if the activity of the neurons of interest is indeed affected by stress signals under physiological conditions. A mapping of stress-activated neurons in the brain would provide candidate brain regions and neuronal populations that can be analyzed in such physiological studies to determine their functions in the central stress mechanism.

Social defeat stress has been widely used as a rodent stress model that is caused by social interaction and as such may be closer to stress in human society than more artificial stressors, such as needle injection, restraint or placement into a new cage (Vinkers et al., 2009), although it is not entirely analogous to heterogeneous interpersonal conflicts in human social conditions (Huhman, 2006). This stress model has become more widely used to determine the pattern of stress-induced neuronal activation in the brain (Kollack-Walker and Newman, 1995; Matsuda et al., 1996; Kollack-Walker et al., 1997; Martinez et al., 1998; Chung et al., 1999; Miczek et al., 1999). However, the results from these studies are inconsistent, probably due to non-psychogenic effects caused by the variations in the procedure, conditions and species (reviewed by Martinez et al., 2002).

Among responses induced by acute psychological stress, an increase in body temperature, known as psychological stress-induced hyperthermia (PSH), is a basic autonomic stress responses observed in many mammalian species (Oka et al., 2001). Although most of such acute stress responses are beneficial in stress coping, intense and long-lasting stressors often cause stress disorders and mental illness, such as psychogenic fever and depression (de Kloet, et al., 2005; Oka and Oka, 2012). For the treatment of stress-related symptoms, benzodiazepine anxiolytics, represented by diazepam, have been clinically used (Ashton, 1994). We have 
shown that systemic administration of diazepam in rats reduces hyperthermia induced by social defeat stress (Lkhagvasuren et al., 2011). Diazepam may exert such clinical and experimental effects through its nonselective action facilitating GABAergic inhibition of neurons that occurs ubiquitously in broad brain areas. However, clinical dosage of diazepam highly selectively alleviates psychogenic symptoms without causing noticeable suppression of other central performances (e.g., sensory and motor systems). This pharmacological property of diazepam indicates that this drug selectively influences the neuronal populations that function in the central stress mechanism. Therefore, neurons that exhibit diazepam-sensitive, stress-induced activation in the brain are potentially involved in the central stress mechanism, and the distribution of such neurons would be important information for understanding not only the central stress circuitries for the development of PSH, but also those for many other autonomic, behavioral and neuroendocrine stress responses.

In the present study, we sought to identify the patterns of neuronal activation in rat forebrain and midbrain following social defeat stress and/or diazepam administration using immunohistochemistry for Fos, a marker of neuronal activation (Sagar et al., 1988). The stress-relief effect of diazepam in the animals used for this Fos study was physiologically confirmed by monitoring stress-induced increases in their body core temperature $\left(T_{\mathrm{c}}\right)$ following diazepam administration. Then, we performed detailed quantification of Fos expression in 113 forebrain and midbrain regions and classified them into four types based on the patterns of Fos expression after the stress/diazepam treatments: 1) stress increased Fos expression, which was decreased by diazepam; 2) stress increased Fos expression, which was unaffected by diazepam; 3) stress increased Fos expression, which was further increased by diazepam; and 4) stress did not increase Fos expression.

\section{EXPERIMENTAL PROCEDURES}

\section{Animals}

Male Wistar rats weighing $190-290 \mathrm{~g}$ and male Long-Evans rats weighing $400-550$ g (SLC, Kurume, Japan) were used as intruders and residents, respectively. Wistar rats were individually caged and Long-Evans rats were pair-caged with age-matched females. Both strains were housed in separate rooms air-conditioned at $24 \pm 2^{\circ} \mathrm{C}$ 
with a standard 12-h light-dark cycle (lights on 7:00-19:00 h) and allowed ad libitum access to food and water.

All procedures conformed to the guidelines of the Ministry of Education, Culture, Sports, Science, and Technology of Japan and to those of the NIH in the USA regarding the care and use of animals for experimental procedures, and were approved by the Ethics Committees of Kyushu University (A22-165-0) and by the Animal Research Committee, Graduate School of Medicine, Kyoto University (MedKyo11095).

\section{Surgery and body temperature monitoring}

We measured $T_{\mathrm{c}}$ of Wistar rats using a telemetry system (Data Sciences International, St Paul, MN, USA). A battery-operated telemetric transmitter (TA10TA-F40) was implanted into the peritoneal cavity of each rat via a midline incision under anesthesia with a mixture of medetomidine $(0.15 \mathrm{mg} / \mathrm{kg})$, midazolam (2 $\mathrm{mg} / \mathrm{kg})$ and butorphanol $2.5 \mathrm{mg} / \mathrm{kg}(0.1 \mathrm{ml} / 10 \mathrm{~g}$ weight, i.p.). After closure of the cavity with suture, the animals were housed individually for 1 week to recover from the surgery under regular health checks. $T_{\mathrm{c}}$ signals were received by an antenna below the rat cage and relayed to a signal processor (Dataquest A.R.T. System, Data Sciences International) connected to a server computer. At least 1 day before the experiment, the telemetric transmitters were activated using a magnet to start recording $T_{\mathrm{c}}$ every $5 \mathrm{~min}$. Only rats that showed stable diurnal changes in $T_{\mathrm{c}}$ were used for the following experiments.

\section{Drug injection and social defeat stress}

On the experimental day, the Wistar rats received an i.p. injection of diazepam (4 $\mathrm{mg} / \mathrm{kg}, 0.4-0.6 \mathrm{ml}$; Wako, Osaka, Japan) or its vehicle. Diazepam was dissolved in physiological saline with $40 \mathrm{mM}$ hydrochloric acid (Shannon and Herling, 1983). In our pilot experiments, we determined the minimum effective dose of diazepam based on its inhibitory effect on social defeat stress-induced increase in $T_{\mathrm{c}}$ and found that 4 $\mathrm{mg} / \mathrm{kg}$ consistently gave a significant inhibitory effect on the PSH without causing noticeable muscle relaxation or hypothermia. To minimize stress from the injection procedure, the solution was quickly injected into the abdominal cavity through the lower abdominal skin, which was exposed to the experimenter by gently bending the 
lower back backward with the base of the tail lifted up. This procedure was performed within the home cages of the Wistar rats, and during the procedure, their forelegs were touching the floor with little movement of the head.

Sixty minutes after the injection, the Wistar rats were exposed to social defeat stress (Stress group) or left undisturbed in their home cages (Control group). The social defeat stress procedure followed our established method (Lkhagvasuren et al., 2011), which was modified from a resident-intruder confrontation procedure (Miczek et al., 1982; Tornatzky and Miczek, 1993). The female of the paired Long-Evans rats was removed from their home cage and in exchange, the Wistar rat (the intruder) was placed into the cage $(40 \mathrm{~cm}$ long $\times 25 \mathrm{~cm}$ wide $\times 20 \mathrm{~cm}$ high) of the male LongEvans rat (the resident) for $60 \mathrm{~min}$. In most cases, the intruder was attacked and defeated by the resident within $5 \mathrm{~min}$ as was evident from freezing behavior or a submissive posture. As soon as the intruder was found defeated, the animals were separated with a wire-mesh partition inserted into the cage. Thereby, the intruder was protected from direct physical contact and injury, but remained in olfactory, visual and auditory contact with the resident for the rest of the stress period. No wound was found on the intruders following this stress procedure. After the stress period, the intruder was returned to its home cage. This injection/stress procedure was performed between 10:00 and 12:00 h, when the circadian changes in $T_{\mathrm{c}}$ were minimal.

The Wistar rats were randomly separated into 4 groups ( $n=4$ per group) and each group was treated with one of the following procedures: i) receiving vehicle injection, then being left undisturbed (Vehicle/Control); ii) receiving vehicle injection followed by social defeat stress (Vehicle/Stress); iii) receiving diazepam injection followed by social defeat stress (Diazepam/Stress); and iv) receiving diazepam injection, then being left undisturbed (Diazepam/Control). These procedures were conducted in the time course as described above (see Fig. 1A). Mean $T_{\mathrm{c}}$ for a 30min period prior to the injection was considered the baseline $T_{\mathrm{c}}$. Peak $T_{\mathrm{c}}$ was taken during the 60-min stress or control period and the change from the baseline $T_{\mathrm{c}}$ is presented as peak $\Delta T_{\mathrm{c}}$ (Fig. 1B). The animals were re-anesthetized at $15 \mathrm{~min}$ after the end of the 60-min period of social defeat stress or undisturbed control and immediately perfused transcardially with $100-150 \mathrm{ml}$ of physiological saline and then

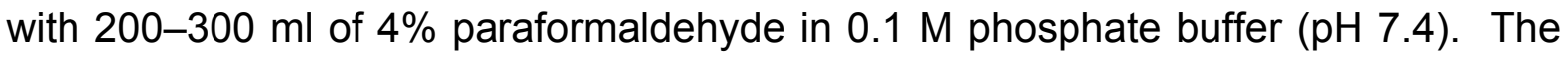


brains were removed, postfixed in the fixative at $4^{\circ} \mathrm{C}$ for $2 \mathrm{~h}$, and then cryoprotected with a $30 \%$ sucrose solution overnight. The tissues were cut into $30-\mu m$-thick frontal sections on a freezing microtome.

\section{Immunohistochemistry}

Fos immunohistochemistry followed our procedure (Nakamura et al., 2002). The brain sections were incubated overnight with an anti-Fos rabbit serum (1:10,00020,000; Ab-5; Oncogene, Cambridge, MA, USA) and then for $1 \mathrm{~h}$ with a biotinylated donkey antibody to rabbit IgG $(10 \mu \mathrm{g} / \mathrm{ml}$; Chemicon, Temecula, CA, USA). The sections were further incubated for $1 \mathrm{~h}$ with avidin-biotinylated peroxidase complex (ABC-Elite, 1:50; Vector, Burlingame, CA, USA). Bound peroxidase was visualized by incubating the sections with a solution containing $0.02 \% 3,3$ '-diaminobenzidine tetrahydrochloride (Sigma), $0.001 \%$ hydrogen peroxide and $50 \mathrm{mM}$ Tris- $\mathrm{HCl}(\mathrm{pH}$ 7.6). The sections were mounted on aminosilane-coated glass slides and coverslipped.

The anti-Fos serum was raised against residues 4-17 of the human Fos protein and has been screened for positive reactivity with floating rat brain sections induced for Fos expression. This antiserum has been confirmed not to react with Jun proteins (manufacturer's technical information) and widely used to label Fos in rat brain (Elmquist et al., 1996; Scammell et al., 1996; Nakamura et al., 2002, 2004).

\section{Anatomy and cell counting}

Most of the anatomical nomenclature and nuclear boundaries in this study followed Paxinos and Watson's stereotaxic rat brain atlas (Paxinos and Watson, 1998). We studied Fos immunoreactivity in 113 forebrain and midbrain regions (listed in Table 1). The anatomical structure of each brain region was identified with cresyl violet staining in adjacent sections. For evaluation of Fos expression, we quantified average densities of Fos-immunoreactive (IR) cells in these brain regions. This quantification method was modified from those used in previous studies that evaluated Fos expression in extensive brain regions (Martinez et al., 1998; Frank et al., 2006). Three digital images of Fos-IR nuclear profiles were taken at randomly selected sites in each brain region (on the right-hand side, if it had a bilateral structure) with a $40 \times$ objective lens under a microscope coupled to a digital camera 
(Nikon) and stored in a computer. The sites where the images were taken were anatomically matched among the animals. A square $(200 \mu \mathrm{m} \times 200 \mu \mathrm{m})$ was set at an arbitrary position within each image and Fos-IR cell nuclei within the square were counted. Figure 2 shows representative images that were used for counting Fos-IR cell nuclei in the dorsomedial hypothalamic nucleus from the 4 experimental groups. The average of the numbers from the three images in a given brain region was expressed as a density of Fos-IR cells (per $0.04 \mathrm{~mm}^{2}$ ). Means \pm S.E.M. of average densities of Fos-IR cells from 4 animals in each treatment group are shown in Table 1. To avoid observer-induced bias, a different, sample-blind observer newly selected sites of image capture for some brain regions, duplicated the quantification procedure and confirmed that the same statistic results were obtained.

Since distribution of Fos-IR cells was generally uniform within most brain regions, we consider that the obtained average densities represent the entire densities of Fos-IR cells in these regions. In some large brain regions in which densities of FosIR cells looked different among their subregions, we quantified Fos-IR cells separately for the subregions. We also tested the validity of our quantification procedure by comparing obtained average densities of Fos-IR cells with actual numbers of Fos-IR cells in the dorsal hypothalamic area and dorsomedial hypothalamic nucleus, which are known as important regions for cardiovascular and neuroendocrine stress responses (Stotz-Potter et al., 1996a). The densities were positively correlated with the actual numbers in both regions (Fig. 3; see also Results).

\section{Statistics}

All data are presented as means \pm S.E.M. Treatment effects on $T_{c}$ over time were evaluated using a two-way repeated measures ANOVA (groups $\times$ time; SPSS for Windows, Version 17). Drug effects on peak $\Delta T_{\mathrm{c}}$ were analyzed using a one-way ANOVA followed by a Bonferroni post hoc test (Fig. 1B). To examine the effect of diazepam itself on the $T_{\mathrm{c}}$ level, baseline $T_{\mathrm{c}}$ and post-injection $T_{\mathrm{c}}$ were compared using a paired $t$-test. Inter-group comparisons of baseline $T_{\mathrm{c}}$ were performed using a one-way ANOVA. Statistical analyses for Fos-IR cell counting data were performed using a two-way ANOVA followed by a Bonferroni post hoc test (stress $\times$ diazepam; Prism 6, GraphPad, La Jolla, CA, USA; Table 1). Correlation between densities and 
actual numbers of Fos-IR cells was examined using a linear regression analysis (Fig. 3). All tests were two-tailed and results with a $P$ value of $<0.05$ were considered significant.

\section{RESULTS}

\section{Effects of diazepam on social defeat stress-induced hyperthermia}

Intruder Wistar rats received an i.p. injection of diazepam or vehicle 60 min before exposure to social defeat stress. Diazepam injection itself did not affect the $T_{\mathrm{c}}$ level (pre-injection 30 -min average, $37.0 \pm 0.1^{\circ} \mathrm{C}$; post-injection average for the 30 -min period immediately before stress or control period, $36.8 \pm 0.1^{\circ} \mathrm{C} ; n=8$ per group, $t_{7}=$ 1.72, $P=0.13$, paired $t$-test). Vehicle-injected rats exhibited an increase in $T_{\mathrm{c}}$ by 2.2 $\pm 0.1^{\circ} \mathrm{C}$ (peak $\Delta T_{c} ; n=4$ ) in response to exposure to social defeat stress (Vehicle/Stress; Fig. 1). The social defeat stress-induced increase in $T_{\mathrm{c}}$ was significantly reduced in diazepam-injected rats (Diazepam/Stress) compared with the Vehicle/Stress group across time (Fig. $1 \mathrm{~A}$; groups, $F_{3,12}=8.59, P<0.01$; time, $F_{32,384}$ $=34.39, P<0.001$; groups $\times$ time, $F_{96,384}=21.79, P<0.001$; two-way repeated measures ANOVA). Even as measured by peak $\Delta T_{\mathrm{c}}$, diazepam injection significantly reduced the social defeat stress-induced increase in $T_{\mathrm{c}}$ (Fig. 1B; $0.9 \pm$ $0.3^{\circ} \mathrm{C}, n=4 ; F_{3,12}=30.43, P<0.001$, one-way ANOVA; Vehicle/Stress vs. Diazepam/Stress, $P=0.001$, Bonferroni post hoc test), but did not affect $T_{\mathrm{c}}$ in control animals (Fig. 1B; Vehicle/Control vs. Diazepam/Control, $P>0.05$ ), consistent with our previous result (Lkhagvasuren et al., 2011). Baseline $T_{\mathrm{C}}$ before injection did not differ among the groups (Fig. $1 \mathrm{~A} ; F_{3,12}=0.49, P=0.70$, one-way ANOVA).

\section{Immunohistochemical analysis of Fos expression}

The Wistar rats whose $T_{\mathrm{c}}$ was recorded were then subjected to Fos study. To evaluate Fos expression, we obtained average densities of Fos-IR cells (Fig. 2) from 113 forebrain and midbrain regions following the stress and drug treatments (Table 1). To test the validity of this analytical procedure, the obtained densities of Fos-IR cells in the dorsal hypothalamic area and dorsomedial hypothalamic nucleus were compared with actual numbers of Fos-IR cells in these regions that were counted in every six frontal sections. The densities were positively correlated with the actual numbers in both regions (Fig. 3; $P<0.05$, linear regression analysis), indicating that 
the present quantification of cell densities reflects actual numbers of Fos-IR cells in brain regions of interest.

We statistically examined the effects of the stress and diazepam treatment on Fos expression in each brain region using a two-way ANOVA, and subsequently performed multiple comparisons (Bonferroni post hoc test) of densities of Fos-IR cells among the four stress/drug treatment groups (Table 1). Comparisons between the Vehicle/Control and Vehicle/Stress groups showed that social defeat stress significantly increased Fos-IR cells in many forebrain and midbrain regions, but did not decrease in any regions we studied (Table 1). The effect of diazepam on the stress-induced Fos expression was examined by comparisons between the Vehicle/Stress and Diazepam/Stress groups. In many of the stress-activated brain regions, the densities of Fos-IR cells that were increased by stress were significantly decreased by diazepam injection (Table 1). We classified these regions as type 1 regions. All brain regions in which the two-way ANOVA detected significant effects of both stress and diazepam and a significant interaction between these two factors, except the magnocellular nucleus of the lateral hypothalamus, were classified as type 1 regions based on the Bonferroni post hoc test (Table 1). Diazepam-induced reduction of stress-induced increase in Fos-IR cell density in type 1 regions is expressed in percentages and listed in Table 2. In most other stress-activated brain regions, diazepam did not exert a significant effect on the stress-induced increase in Fos-IR cells. These regions were classified as type 2 regions (Table 1). A type 3 region was defined as a region where the density of Fos-IR cells was increased by stress and diazepam further increased the density. The medial habenular nucleus was the only region classified as a type 3 region. The rest of the forebrain and midbrain regions, in which stress did not affect densities of Fos-IR cells, were classified as type 4 regions (Table 1 ).

To examine the effects of diazepam on basal Fos expression, we compared densities of Fos-IR cells between the Vehicle/Control and Diazepam/Control groups. Diazepam injection itself did not affect basal Fos expression in most regions, but did significantly increase the basal densities of Fos-IR cells in the caudal part of the central amygdaloid nucleus, magnocellular nucleus of the lateral hypothalamus and medial habenular nucleus, and decreased those in the supraoptic nucleus and posterior hypothalamic area (Table 1). 


\section{Social defeat stress-induced Fos expression and effects of diazepam in forebrain and midbrain regions}

Cerebral cortex. Most cerebral cortices were classified as type 1 regions. Social defeat stress remarkably increased densities of Fos-IR cells in broad areas of the cerebral cortex (Fig. 4). Sensory cortices, such as the somatosensory, visual and auditory cortices, and the parietal cortex contained especially many Fos-IR cells following social defeat stress in vehicle-injected rats (Table 1). Stress also significantly increased densities of Fos-IR cells in the orbital, frontal, motor, prelimbic, infralimbic, cingulate, retrosplenial, insular, ectorhinal and perirhinal cortices. In the motor and somatosensory cortices, stress-induced Fos expression was prominent in layers IV and VI (Fig. 4C). Fos-IR cells were also increased in layers II, III and V following stress, but their distribution was relatively sparse. Layer I contained very few Fos-IR cells. In the piriform cortex, layer II exhibited a remarkable increase in Fos-IR cells in response to stress, whereas stress-induced Fos expression in layer III was moderate (Table 1 and Fig. 4D). Layer I of the piriform cortex contained very few Fos-IR cells. The anterior olfactory nucleus also exhibited a significant increase in Fos-IR cells following stress. The entorhinal cortex did not show significant changes in the density of Fos-IR cells with the stress and drug treatments.

Systemic injection of diazepam significantly reduced the stress-induced increases in densities of Fos-IR cells in these cerebral cortical regions except layer III of the piriform cortex (Table 1 and Fig. 4). Diazepam treatment especially exerted strong inhibitory effects in the orbital, frontal, parietal, prelimbic, secondary cingulate, retrosplenial and insular cortices and the anterior olfactory nucleus, in which the stress-induced increases in Fos-IR cells were reduced by more than $80 \%$ (Table 2). The stress-induced increases in Fos-IR cells in the motor, somatosensory, auditory, infralimbic, primary cingulate, ectorhinal, perirhinal and piriform (layer II) cortices were reduced by $50-80 \%$ by diazepam, and that in the visual cortex was reduced by $41 \%$ (Table 2). The stress-induced Fos expression in layers II-VI of the isocortex was obviously reduced by diazepam (Fig. 4C). Diazepam injection did not affect the basal expression of Fos in any of the cerebral cortical regions we studied (Table 1).

Hippocampal formation. Social defeat stress significantly increased densities of Fos-IR cells in the Ammon's horn and ventral subiculum, but not in the dentate 
gyrus (Table 1 and Fig. 5A and B). Fos-IR cells in the Ammon's horn following stress were mostly distributed in the pyramidal cell layer and the density was higher in the CA1 region than in the CA3 region (Fig. 5A). Diazepam injection reduced the stress-induced Fos expression in the Ammon's horn and ventral subiculum to the basal level (94-115\% reduction; Tables 1 and 2 and Fig. 5A and B), but did not affect the basal Fos expression in the control rats.

Septal region. Stress significantly increased the densities of Fos-IR cells in the lateral septal nucleus, medial septal nucleus, nucleus of the diagonal band, and bed nucleus of the stria terminalis (BNST), although the increase in the medial septal nucleus was relatively small (Table 1 and Fig. 5C). Diazepam injection reduced the stress-induced Fos expression in the lateral septal nucleus, medial septal nucleus and nucleus of the diagonal band by 75-95\% (Tables 1 and 2). In the BNST, diazepam significantly reduced the stress-induced increase in the Fos-IR cell density in the ventral divisions (96\% reduction), but not in the dorsal divisions (Table 1 and Fig. 5C). Diazepam did not affect the basal levels of Fos expression in these septal regions.

Basal ganglia. In the striatum, the caudate putamen showed a low basal level of Fos-IR cell density (Table $1 ; 0.9 \pm 0.3$ cells $/ 0.04 \mathrm{~mm}^{2}$ ), compared with the accumbens nucleus $\left(28.4 \pm 6.0\right.$ cells $\left./ 0.04 \mathrm{~mm}^{2}\right)$. The globus pallidus also showed low basal Fos expression $\left(0.5 \pm 0.5\right.$ cells $\left./ 0.04 \mathrm{~mm}^{2}\right)$ in contrast to the ventral pallidum $\left(6.8 \pm 1.6\right.$ cells $\left./ 0.04 \mathrm{~mm}^{2}\right)$. Social defeat stress significantly increased the densities of Fos-IR cells in all these regions, although the increase in the globus pallidus was small (Table 1). The stress-induced increases in Fos-IR cells in these regions were all reduced by diazepam injection by $84-120 \%$ (Table 2). Stress also increased densities of Fos-IR cells in the navicular nucleus of the basal forebrain and the endopiriform nucleus (Fig. 4D) and these increases were reduced by diazepam (Tables 1 and 2). Fos expression in the claustrum was not significantly increased by stress. Diazepam injection had no effect on the basal Fos expression levels in the basal ganglia.

Amygdala. The cortical amygdaloid nucleus, medial amygdaloid nucleus, lateral amygdaloid nucleus and basomedial amygdaloid nucleus exhibited significant stress-induced increases in densities of Fos-IR cells, which were all significantly 
reduced by diazepam (74-83\% reduction; Tables 1 and 2 and Fig. 5D). In contrast, the central amygdaloid nucleus exhibited no increase in Fos expression in response to social defeat stress (Table 1 and Fig. 5D). This region exhibited higher basal expression of Fos (rostral part, $39.2 \pm 4.8$ cells $/ 0.04 \mathrm{~mm}^{2}$; caudal part, $41.5 \pm 8.4$ cells/0.04 $\mathrm{mm}^{2}$ ) than other amygdaloid regions (3.4-12.7 cells/0.04 $\mathrm{mm}^{2}$; Table 1 and Fig. 5D), and diazepam injection significantly increased the basal Fos-IR cell density in the caudal part $\left(84.7 \pm 5.6\right.$ cells $\left./ 0.04 \mathrm{~mm}^{2}\right)$, but not in the rostral part $(57.1$ \pm 2.5 cells $/ 0.04 \mathrm{~mm}^{2}$ ). The basolateral amygdaloid nucleus did not show a significant increase in Fos-IR cell density following stress.

Preoptic area and hypothalamus. Many of preoptic and rostral hypothalamic regions exhibited relatively high basal densities of Fos-IR cells compared to other forebrain regions (Table 1). In the preoptic area, social defeat stress increased densities of Fos-IR cells in the medial preoptic area, lateral preoptic area, septohypothalamic nucleus, parastrial nucleus and ventrolateral preoptic nucleus, but not in the organum vasculosum lamina terminalis, median preoptic nucleus or ventromedial preoptic nucleus (Table 1 and Figs. 5C and 6A). All the stress-induced increases in Fos expression in the preoptic area were significantly reduced by diazepam injection (58-121\% reduction; Tables 1 and 2 and Figs. 5C and 6A). Diazepam exerted an especially strong inhibitory effect on stress-induced Fos expression in the parastrial nucleus $(121 \%$ reduction; Table 2) and septohypothalamic nucleus (91\%). Diazepam did not affect the basal levels of Fos expression in any of the preoptic regions.

Stress increased densities of Fos-IR cells in most rostral hypothalamic regions: anterior hypothalamic area, suprachiasmatic nucleus, periventricular hypothalamic nucleus and paraventricular hypothalamic nucleus (Table 1 and Fig. 6B and C). The suprachiasmatic nucleus exhibited a remarkably high basal level of Fos expression $\left(144.1 \pm 21.5\right.$ cells $\left./ 0.04 \mathrm{~mm}^{2}\right)$ and stress further increased the Fos-IR cell density to $307.4 \pm 4.7$ cells/0.04 mm² (Table 1 and Fig. 6B). The stress-induced Fos expression in this nucleus was suppressed by diazepam injection to the baseline level (115.6 \pm 0.7 cells/0.04 mm²; 117\% reduction; Tables 1 and 2 and Fig. 6B). In the paraventricular hypothalamic nucleus, the Fos-IR cell density in the Vehicle/Stress group was high in the medial parvicellular $(121.4 \pm 4.9$ cells/0.04 $\mathrm{mm}^{2}$; Table 1) and lateral magnocellular parts $\left(99.1 \pm 17.1\right.$ cells $\left./ 0.04 \mathrm{~mm}^{2}\right)$ and was 
relatively moderate in the ventral part $\left(63.2 \pm 4.9\right.$ cells $\left./ 0.04 \mathrm{~mm}^{2}\right)$. Diazepam strongly reduced the stress-induced Fos expression in the medial parvicellular part by $87 \%$ and in the ventral part by $81 \%$, but failed to significantly reduce that in the lateral magnocellular part (Tables 1 and 2 and Fig. 6C). The stress-induced increase in the Fos-IR cell density in the periventricular hypothalamic nucleus was also strongly reduced by diazepam (82\% reduction; Table 2 ). Diazepam did not significantly inhibit the stress-induced Fos expression in the anterior hypothalamic area. In the supraoptic nucleus, stress did not significantly change the density of Fos-IR cells, whereas the basal level of Fos expression was lowered by diazepam (Table 1).

In caudal hypothalamic regions, stress increased densities of Fos-IR cells in the arcuate nucleus, dorsal hypothalamic area, dorsomedial hypothalamic nucleus, perifornical nucleus, peduncular part of the lateral hypothalamus, and posterior hypothalamic area (Table 1 and Fig. 7). Diazepam injection reduced the stressinduced increases in Fos expression in all these caudal hypothalamic regions (Tables 1 and 2 and Fig. 7). The inhibitory effect of diazepam on the stress-induced Fos expression was especially intense in the arcuate nucleus (rostral part, $85 \%$ reduction; caudal part, 98\%; Table 2), posterior hypothalamic area (93\%) and perifornical nucleus (83\%) and was relatively moderate in the peduncular part of the lateral hypothalamus (74\%), dorsal hypothalamic area (72\%) and dorsomedial hypothalamic nucleus (57\%). It should be noted that the basal level of Fos expression in the posterior hypothalamic area was also reduced by the diazepam treatment (Table 1). The densities of Fos-IR cells in the ventromedial hypothalamic nucleus and in the magnocellular nucleus of the lateral hypothalamus were not affected by stress following vehicle injection, but were slightly increased by stress following diazepam injection. The magnocellular nucleus of the lateral hypothalamus also exhibited an increase in the basal level of Fos expression following diazepam treatment, whereas this drug did not significantly change the basal Fos expression in the ventromedial hypothalamic nucleus (Table 1).

All regions in the mammillary body that we studied were classified as type 1 regions. In the premammillary nucleus, social defeat stress drastically increased the Fos-IR cell density in the ventral part to $117.9 \pm 12.2$ cells $/ 0.04 \mathrm{~mm}^{2}$, while the density in the dorsal part following stress was $72.5 \pm 9.1$ cells $/ 0.04 \mathrm{~mm}^{2}$ (Table 1 and 
Fig. 7C). Stress also increased densities of Fos-IR cells in the supramammillary nucleus, medial mammillary nucleus and ventral tuberomammillary nucleus (Fig. 7C). A dense cluster of Fos-IR cells was observed in the ventral tuberomammillary nucleus of the Vehicle/Stress group (Fig. $7 \mathrm{C}_{2}$ ). The stress-induced increases in Fos expression in all these mammillary regions were significantly reduced by diazepam injection (59-104\% reduction; Tables 1 and 2 and Fig. 7C). Diazepam did not affect the basal expression of Fos in these mammillary regions.

Thalamus and habenula. Social defeat stress increased densities of Fos-IR cells in both medial and lateral habenular nuclei (Table 1). The Fos-IR cells in the lateral habenular nucleus following stress were clustering in its medial part, while those cells in the medial habenular nucleus were sparsely distributed (Fig. 8A). Diazepam injection reduced the stress-induced Fos expression in the lateral habenular nucleus by $68 \%$ (Tables 1 and 2 and Fig. $8 \mathrm{~A}$ ). On the other hand, diazepam significantly increased both basal and stress-induced Fos expression in the medial habenular nucleus (Table 1 and Fig. 8A).

Many thalamic regions were classified as type1 regions. Most of the association, motor and sensory thalamic nuclei exhibited relatively low basal levels of Fos expression (Table 1). In the association, midline and intralaminar thalamic nuclei, social defeat stress increased the densities of Fos-IR cells in the anterodorsal, anteromedial, anteroventral, mediodorsal, laterodorsal, reticular, submedius, central lateral, central medial, intermediodorsal, paracentral, paraventricular, reuniens and rhomboid nuclei (Table 1). The paraventricular nucleus exhibited high basal Fos expression $\left(41.5 \pm 3.8\right.$ cells $/ 0.04 \mathrm{~mm}^{2}$; Table 1$)$ and the dense distribution of Fos-IR cells in this nucleus following stress was remarkable (Fig. 8). Also, dense clusters of Fos-IR cells distributed in the midline and intralaminar nuclei and in the anterodorsal, anteromedial, anteroventral and laterodorsal nuclei following stress formed a shape of "a bird with its wings spread" (Fig. $\left.8 \mathrm{~B}_{2}\right)$. In contrast to these thalamic nuclei, the mediodorsal nucleus contained sparsely distributed Fos-IR cells following stress (Fig. $8 \mathrm{~B}_{2}$ ). The paratenial nucleus did not show significant changes in the density of FosIR cells through the experimental treatments. Diazepam injection reduced the stress-induced Fos expression in the anterodorsal, anteromedial, anteroventral, mediodorsal, laterodorsal, reticular, submedius, central lateral, central medial, intermediodorsal, paraventricular and rhomboid nuclei by 40-98\% (Tables 1 and 2 
and Fig. 8). The stress-induced increases in the Fos-IR cell densities in the paracentral and reuniens nuclei were not significantly inhibited by diazepam (Table 1 and Fig. 8B).

In the motor and sensory thalamic nuclei, stress increased densities of Fos-IR cells in the ventral medial nucleus, medial geniculate nucleus, posterior nucleus and ventral posterior complex (Table 1 and Fig. 8B). Diazepam reduced the stressinduced Fos expression in the ventral medial nucleus, posterior nucleus and ventral posterior complex by $64-99 \%$, but failed to significantly reduce that in the medial geniculate nucleus (Tables 1 and 2 and Fig. 8B). Although the lateral geniculate nucleus exhibited a high basal level of Fos expression $\left(41.3 \pm 4.6\right.$ cells $\left./ 0.04 \mathrm{~mm}^{2}\right)$, the Fos-IR cell density in this nucleus did not significantly change in response to stress or diazepam injection (Table 1). Neither ventrolateral nucleus nor ventral anterior nucleus showed significant changes in the density of Fos-IR cells with stress or diazepam. Diazepam did not affect the basal levels of Fos expression in any of the thalamic regions we studied.

The zona incerta exhibited an increase in the density of Fos-IR cells in response to stress, and diazepam injection suppressed the stress-induced increase in Fos expression to the baseline level (Tables 1 and 2 and Fig. 7B). Diazepam did not affect the basal Fos expression in this region.

Midbrain. Social defeat stress increased densities of Fos-IR cells in the superior colliculus, periaqueductal gray, interfascicular nucleus, paranigral nucleus, ventral tegmental area, cuneiform nucleus, ventral tegmental nucleus, linear nucleus of the raphe, median raphe nucleus and dorsal raphe nucleus (Table 1 and Fig. 9). In the periaqueductal gray, the stress-induced increases in the Fos-IR cell densities in the lateral and ventrolateral parts were attenuated by diazepam injection by $48 \%$ and $78 \%$, respectively, whereas diazepam did not significantly inhibited the stressinduced Fos expression in the dorsal (dorsomedial and dorsolateral) parts (Tables 1 and 2 and Fig. 9A). In the raphe nuclei, diazepam injection reduced the stressinduced Fos expression in the median raphe nucleus by $131 \%$ and in the dorsal raphe nucleus by $63 \%$, but failed to significantly reduce that in the linear nucleus of the raphe (Tables 1 and 2 and Fig. 9). In the nigrotegmental area, Fos-IR cells following stress were mostly distributed in a zonal area consisting of the interfascicular and paranigral nuclei (Fig. 9C). The stress-induced increase in the 
Fos-IR cell density in the ventral tegmental area was small (Table 1). Diazepam reduced the stress-induced Fos expression in these nigrotegmental regions by 5494\% (Table 2 and Fig. 9C). Fos-IR cells were scarcely detected in the substantia nigra in any of the experimental groups (Fig. 9C). The stress-induced increases in the Fos-IR cell densities in the cuneiform nucleus and ventral tegmental nucleus were reduced by diazepam by $60 \%$ and 136\%, respectively (Tables 1 and 2 and Fig. 9B). The stress-induced Fos expression in the superior colliculus was not significantly reduced by diazepam (Table 1). The retrorubral field, red nucleus and inferior colliculus did not show significant changes in the densities of Fos-IR cells in response to the stress and diazepam treatments (Table 1). Diazepam did not alter the basal levels of Fos expression in the midbrain regions.

\section{DISCUSSION}

In the present study, we investigated social defeat stress-induced neuronal activation in a broad area of rat forebrain and midbrain through immunohistochemical detection of Fos as a marker and also examined effects of systemic injection of diazepam on stress-induced neuronal activation. Social defeat stress is regarded as a rodent stress model that is close to stress in human society (Vinkers et al., 2009). The distribution of neurons activated by this stress likely reflects the central neural processing for perception and integration of psychosocial stress signals as well as for autonomic and somatic (behavioral) motor outputs to cope with the stressor. Rats exposed to social defeat stress in the present study exhibited a rapid increase in their $T_{\mathrm{C}}$ and systemic injection of diazepam given prior to the stress exposure significantly attenuated the stress-induced hyperthermic response, physiologically confirming the stress-relief effect of diazepam. These responses of body temperature to psychological stress and diazepam are consistent with previous studies in rodents (Lecci et al., 1990; Zethof et al., 1995; Lkhagvasuren et al., 2011) and presumably homologous to stress responses observed in humans (Björkqvist, 2001). The incompleteness of the inhibition of PSH by diazepam in the present study may be partly due to the low dose of diazepam that we chose to avoid a hypothermic effect by itself. This incomplete effect of diazepam might also suggest the existence of a diazepam-insensitive mechanism in the stress-processing neural system. 
Although the confrontation with an aggressive resident is the major stressor in the social defeat stress model, the present stress procedure also provided intruder rats with stress from being placed in a novel environment. A better control handling to separate the effect of social stress from the other might be to transfer rats to a foreign cage without a resident. However, we have seen that cage-transfer handling induces moderate hyperthermia, although weaker than that caused by social defeat stress. Such a control treatment likely induces substantial Fos expression and masks the neuronal activation by social stress especially in the cerebral cortices, which are highly sensitive to sensory and emotional stimuli. Therefore, we left control rats undisturbed and there is a caveat that the stress-induced responses in the present study were potentially caused by complex psychological stressors from social interaction and novel environment.

Exposure of vehicle-injected rats to social defeat stress increased Fos-IR cells in many forebrain and midbrain regions. The present quantification of Fos-IR cells was made by obtaining an average density of Fos-IR cells in each region. Similar methods have been used to quantify Fos-expressing cells in extensive brain regions (Beck and Fibiger, 1995; Martinez et al., 1998; Frank et al., 2006). The validity of the present quantification was confirmed by the positive, significant correlation between the average densities and actual numbers of Fos-IR cells in the dorsal hypothalamic area and dorsomedial hypothalamic nucleus (Fig. 3). Although expression of Fos in some rat brain regions following exposure to acute social defeat stress has been reported (Martinez et al., 1998, 2002; Chung et al., 2000), the present study provides further detailed distribution of Fos-IR cells in more than 100 forebrain and midbrain regions of rats exposed to social defeat stress. In another support of the validity of the present experimental procedure, the social defeat stress-induced Fos expression in the reported regions was overall reproduced in the present study, although it is difficult to simply compare Fos expression in some forebrain regions due to the differences in anatomical subdivisions between the present and previous studies. The present statistical comparisons of Fos-IR cell densities among the experimental groups might be conservative due to the limited size of each group; however, deviations of Fos-IR cell densities within groups were overall small and therefore, the statistical tests could identify many brain regions that exhibited diazepam-sensitive, stress-induced neuronal activation from the extensive forebrain and midbrain areas. 
The large number of type 1 regions, in which social defeat stress increased FosIR cells and systemically injected diazepam significantly reduced the stress-induced increases in Fos-IR cells, indicates the inhibitory effect of diazepam on neuronal activity in broad areas of the forebrain and midbrain through its action facilitating GABAergic transmission. The reduction of Fos-IR cells may be partly due to a nonspecific effect of diazepam on neuronal activity. However, diazepam injection did not affect basal expression of Fos in type 1 regions (except the posterior hypothalamic area). This observation clearly indicates that diazepam's inhibitory effect is selective in stress-induced neuronal activation and is consistent with the pharmacological property of diazepam that clinical dosage of this drug selectively influences the central stress mechanisms without causing remarkable nonspecific suppression of other central systems. Therefore, the neuronal populations that exhibit diazepam-sensitive, stress-induced activation (i.e., type 1 neurons) are likely involved in the central stress mechanisms, and physiological characterization of type 1 neurons could lead to elucidation of the central stress circuitries. Here, we discuss the potential functional relevance of the present distribution of Fos-IR cells to the development of PSH as well as to other autonomic, neuroendocrine, behavioral and emotional stress responses.

\section{Hypothalamic expression of Fos: relevance to autonomic and neuroendocrine stress responses}

As shown by the present telemetry recordings, $\mathrm{PSH}$ is a remarkable autonomic response caused by psychological stress. This response is driven by central efferent pathways originated from the hypothalamus (Oka and Oka, 2012), which have yet to be identified. The stress-induced increase in body temperature is supported by evoked heat production in brown adipose tissue (BAT), and sympathetic premotor neurons controlling BAT thermogenesis express Fos in response to social defeat stress (Lkhagvasuren et al., 2011). These sympathetic premotor neurons are distributed in the rostral medullary raphe region including the rostral raphe pallidus and raphe magnus nuclei and mediate the sympathetic outflow to BAT for driving cold-defensive and febrile thermogenesis (Nakamura et al., 2004). Of interest is how forebrain stress signals activate the medullary sympathetic premotor neurons to drive the stress-induced thermogenesis in BAT. One of the candidates for the brain regions that provide excitatory signals to the sympathetic premotor neurons is the 
dorsomedial hypothalamus that consists of the dorsomedial hypothalamic nucleus and dorsal hypothalamic area. There is a population of neurons in the dorsomedial hypothalamus that directly project to the rostral medullary raphe region (Hosoya et al., 1987; Samuels et al., 2004; Nakamura et al., 2005). Although it is unknown whether this direct projection mediates the excitatory thermogenic drive to activate the sympathetic premotor neurons, the present study showed that social defeat stress increases Fos-expressing cells in the dorsomedial hypothalamus. This Fos expression was attenuated by diazepam in parallel with its inhibitory effect on PSH. These findings support the possibility that the dorsomedial hypothalamic neurons are involved in the stress-induced thermogenic drive to BAT. Consistently, in vivo physiological studies have revealed that inactivation of neurons in the dorsomedial hypothalamus with local nanoinjections of muscimol, a neuronal inhibitor, reverses BAT thermogenesis evoked by skin cooling or pyrogenic stimulation (Madden and Morrison, 2004; Nakamura et al., 2005; Nakamura and Morrison, 2007). Muscimol injections into the dorsomedial hypothalamus also inhibit cardiovascular and neuroendocrine responses to stress (Stotz-Potter et al., 1996a,b). The effect of inactivation of dorsomedial hypothalamic neurons on the development of PSH should be tested.

Another neuronal population that potentially provides a thermogenic input to sympathetic premotor neurons in the rostral medullary raphe region is orexin neurons, which are distributed only around the perifornical nucleus of the lateral hypothalamus. There is a direct projection of orexin neurons to the rostral medullary raphe region (Berthoud et al., 2005). We found that cells in the perifornical nucleus exhibit social defeat stress-induced Fos expression, which is inhibited by diazepam. Consistent with the possibility that orexin neurons are involved in the thermogenic responses to social stress, an artificial handling stress induces Fos expression in orexin-containing neurons in mice and diazepam inhibits it (Zhang et al., 2010; Panhelainen and Korpi, 2012). Although hyperthermia induced by handling stress is attenuated by genetic ablation of orexin neurons, ablation of the orexin gene does not affect the PSH (Zhang et al., 2010). Therefore, co-transmitters released from orexin neurons, but not orexin, seem to be involved in the development of PSH. On the other hand, orexin injection into the fourth ventricle induces Fos expression in the rostral medullary raphe region (Berthoud et al., 2005) and nanoinjection of orexin 
into this medullary region elicits BAT thermogenesis (Tupone et al., 2011). These findings suggest that orexin released in the rostral medullary raphe region has a potency to activate sympathetic premotor neurons to drive BAT thermogenesis. However, the orexin-mediated medullary mechanism for thermogenic sympathetic drive may not be simple because injection of a putative orexin receptor antagonist into this medullary region enhances, instead of blocking, BAT thermogenesis (Tupone et al., 2011) and infrared thermography in free-moving rats cannot detect BAT thermogenesis following orexin injection into this medullary region (Luong and Carrive, 2012). It is also possible that orexin neurons contribute to stress responses through their divergent projections to broad brain areas (Peyron et al., 1998).

The preoptic area is known as a center for thermoregulation and fever (Morrison and Nakamura, 2011; Nakamura, 2011). However, whether the preoptic area is involved in the development of PSH is unknown. Thermosensory signals from cutaneous warm and cool receptors, which are required for immediate thermoregulatory responses to changes in environmental temperature, are transmitted to the median preoptic nucleus (Nakamura and Morrison, 2008a, 2010). Stimulation of neurons in the median preoptic nucleus elicits BAT thermogenesis (Nakamura and Morrison, 2008b). In the present study, however, social defeat stress did not increase Fos-expressing neurons in the median preoptic nucleus, suggesting that $\mathrm{PSH}$ is developed without affecting the tone of the ascending thermosensory signaling to the preoptic area. In contrast to the median preoptic nucleus, stimulation (disinhibition) of neurons in the medial preoptic area inhibits BAT thermogenesis (Nakamura and Morrison, 2007, 2008b) and inhibition of the same area evokes BAT thermogenesis and increases ACTH secretion (Osaka, 2004; Zaretsky et al., 2006). Inconsistent with this sympathoinhibitory role, the medial preoptic area exhibited stress-induced neuronal activation (Fos expression), which was inhibited by diazepam. These stress-activated neurons might provide a sympathoexcitatory input directly to the rostral medullary raphe region, as skin cooling-activated preoptic neurons do (Tanaka et al., 2011). However, the distribution of the stress-activated neurons was not limited to the medial preoptic area, but also expanded to the lateral preoptic area, parastrial nucleus and septohypothalamic nucleus (Figs. $5 \mathrm{C}_{2}$ and $6 \mathrm{~A}_{2}$ ). A part of these neurons might be involved in stress responses other than $\mathrm{PSH}$, for example, activation of 
hypothalamo-pituitary-adrenocortical responses through glutamatergic innervation of the paraventricular hypothalamic nucleus upon receiving inputs from limbic forebrain regions (Herman et al., 2004).

PSH and infection-induced fever are similar physiological responses that both increase body temperature through sympathetic activation of effector functions including BAT thermogenesis. The mechanism for developing fever has been well studied. At infection, stimulated immune cells release cytokines, which then induce expression of cyclooxygenase-2 and microsomal prostaglandin $E$ synthases in brain vasculature to synthesize $\mathrm{PGE}_{2}$ (Yamagata et al., 2001). The produced PGE 2 acts on prostaglandin EP3 receptors expressed in neurons in the median preoptic nucleus and medial preoptic area (Nakamura et al., 1999, 2000; Lazarus et al., 2007). These EP3 receptor-expressing neurons are mostly GABAergic neurons that likely provide tonic inhibition on hypothalamic and medullary sympathoexcitatory neurons when $\mathrm{PGE}_{2}$ is absent under non-febrile conditions (Nakamura et al., 2002, 2005). $\mathrm{PGE}_{2}$ triggers febrile sympathetic outflow mechanisms likely by reducing the tonic firing activity of the inhibitory preoptic neurons through EP3 receptors, and thereby, disinhibits the sympathoexcitatory neurons (Nakamura, 2011). Comparison of the present distribution of Fos-IR cells following stress with those following febrile stimuli shows a clear difference in the neuronal populations recruited for stress coping and for acute inflammatory responses. For example, intravenous administration of the exogenous pyrogen lipopolysaccharide (LPS), mimicking systemic infection, or nanoinjection of $\mathrm{PGE}_{2}$ into the preoptic area evokes fever and induces remarkable Fos expression in the ventromedial preoptic nucleus, which is located immediately lateral to the organum vasculosum lamina terminalis (Elmquist et al., 1996; Scammell et al., 1996). LPS also induces Fos expression in the organum vasculosum lamina terminalis (Elmquist et al., 1996). Although whether neurons in these preoptic sites are involved in the development of fever is unknown, these neurons might also be controlled by the tonic inhibitory input from EP3 receptor-expressing preoptic neurons and that their disinhibition through the action of $\mathrm{PGE}_{2}$ might contribute to fever or other acute inflammatory responses. In contrast to the confined distribution of these pyrogen-responsive neurons in the medial part of the preoptic area, social defeat stress did not significantly increase Fos expression in the ventromedial preoptic nucleus or organum vasculosum lamina terminalis, but 
activated preoptic neurons broadly spreading out to the lateral preoptic area (Fig. $6 \mathrm{~A}_{2}$ ). The difference in the preoptic distribution of neurons activated by social stress and by pyrogenic stimuli suggests that the mechanism for $\mathrm{PSH}$ does not involve the $\mathrm{PGE}_{2}-\mathrm{EP} 3$ mechanism in the preoptic area. This dissociation of the mechanisms for $\mathrm{PSH}$ and fever is supported by the findings that mice lacking EP3 receptors, which fail to develop fever, can exhibit intact PSH (Oka et al., 2003) and that PSH is resistant to indomethacin, an antipyretic blocking the production of $\mathrm{PGE}_{2}$ by inhibiting cyclooxygenases (Lkhagvasuren et al., 2011). Consistent with the dissociation of the mechanism of PSH from immune signaling, the plasma levels of the pyrogenic cytokines in a patient with psychogenic fever were below their detectable levels (Hiramoto et al., 2009).

The paraventricular hypothalamic nucleus is one of the brain regions closely related to autonomic and neuroendocrine stress responses (Sawchenko et al., 1996). In this nucleus, the medial parvicellular part contains neurosecretory cells projecting to the median eminence, where they release corticotropin releasing hormone and thyrotropin releasing hormone, as well as autonomic neurons innervating sympathetic (spinal cord) and parasympathetic (dorsal vagal complex) preganglionic neurons. On the other hand, the lateral magnocellular part primarily contains neuroendocrine neurons projecting to the posterior pituitary and releasing oxytocin and vasopressin (Swanson and Sawchenko, 1980; Ferguson et al., 2008). Oxytocincontaining neurons in this part also innervate various forebrain regions (Knobloch et al., 2012). We observed stress-induced increases in Fos-IR cells in all the subregions of this nucleus, confirming the important role of this nucleus in coping with psychosocial stressors through driving the autonomic and neuroendocrine efferents. Consistent with this observation, social defeat stress increases the plasma ACTH level (Wotjak et al., 1996). However, social defeat stress does not change the plasma level of oxytocin or vasopressin (Wotjak et al., 1996), although the same stress increases oxytocin release from nerve endings in the septum (Ebner et al., 2000). The lack of social defeat stress-induced plasma release of oxytocin or vasopressin is consistent with the present observation that social defeat stress did not induce Fos expression in the supraoptic nucleus, another region that contains neuroendocrine neurons releasing these hormones through the posterior pituitary (Meister, 1993). These findings suggest that social defeat stress drives 
oxytocinergic neurons innervating the forebrain, but not oxytocin- or vasopressinreleasing neuroendocrine neurons in the paraventricular hypothalamic nucleus or supraoptic nucleus. The inhibitory effect of diazepam on the stress-induced Fos expression was not uniform in the paraventricular hypothalamic nucleus. Diazepam significantly inhibited the social defeat stress-induced Fos expression in its medial parvicellular and ventral parts, whereas a substantial number of cells in the lateral magnocellular part remained to express Fos following the Diazepam/Stress treatment. Effect of diazepam on stress-induced increase in plasma ACTH or corticosterone is inconsistent among studies (Bizzi et al., 1984; Eisenberg, 1993; Groenink et al., 1996; Kalman et al., 1997) and diazepam's effect on the stressinduced oxytocin release from nerve endings in the forebrain has not been tested as yet. Together with our observation, diazepam may exert differential effects on autonomic and neuroendocrine neurons in the paraventricular hypothalamic nucleus--more effective in stress-induced activation of sympathetic efferents from this nucleus.

\section{Circuitries for increasing arousal and awareness during stress}

Intense Fos expression in response to social defeat stress was observed in the brain regions related to arousal and awareness. Stress-induced Fos expression in the neocortex and the midline and intralaminar nuclei of the thalamus was prominent and the Fos expression in most of these regions was inhibited by diazepam. The midline and intralaminar thalamic nuclei send axonal projections to the cerebral cortex and provide the necessary arousal of cortical and subcortical regions to support information processing that is correlated with awareness (Van der Werf et al., 2002). Therefore, stress-induced activation of neurons in these thalamic nuclei likely leads to the increase in vigilance that is necessary for awareness of incoming information during stress exposure. Social defeat stress induced relatively intense Fos expression in neocortical layers IV and VI. In the local cortical circuit, spiny neurons in layer IV receive abundant thalamic inputs and project to corticothalamic projection neurons in layer VI (Kaneko, 2013). This thalamocortical recurrent circuit is proposed to serve as the basis of autonomous activity of the neocortex (Kaneko, 2013). According to this model, the stress-induced Fos expression in layers IV and VI suggests that stress signaling facilitates the activity of the thalamocortical loop probably to increase the arousal level of the animals. The diazepam-induced 
reduction of the stress-induced Fos expression in the midline and intralaminar thalamic nuclei as well as in their projection regions in the cerebral cortex likely reflects the inhibitory effect of this drug on the vigilance raised in association with stress (Prince et al., 1986). The stress-induced Fos expression in the neocortex and the midline and intralaminar thalamic nuclei apparently contrasts with few Fos-IR cells in the same regions following LPS injection (Elmquist et al., 1996), showing another fundamental difference in the central structures and systems that are recruited for stress responses and acute inflammatory responses. In the thalamus, the paraventricular thalamic nucleus also exhibited intense Fos expression following stress. This nucleus provides projections to the prelimbic and infralimbic cortices (Van der Werf et al., 2002), where we observed intense Fos expression in response to stress. The prelimbic and infralimbic cortices are involved in autonomic and neuroendocrine responses to emotional stress (Radley et al., 2006).

Social defeat stress-induced increase in Fos expression in the ventral tuberomammillary nucleus seems to reflect the arousal state evoked by the stress. The ventral tuberomammillary nucleus contains a dense cluster of histamine neurons, whose activation promotes arousal and maintains high vigilance state through their axonal projections to broad areas throughout the brain including the cerebral cortex (Thakkar, 2011). Diazepam-induced significant reduction of the stress-induced Fos expression in this nucleus is consistent with the effect of this agent that calms the extreme tension in stressful conditions. When promoting sleep, histamine neurons in the ventral tuberomammillary nucleus are inhibited by a strong GABAergic input from the ventrolateral preoptic nucleus (Sherin et al., 1998), where stress-induced expression of Fos was observed in the present study. This Fos expression may be exhibited by the ventrolateral preoptic neurons that show higher discharge rates in awakening than non-REM sleep, which constitute one quarter of neurons in this nucleus (Szymusiak et al., 1998). Serotonin neurons in midbrain raphe nuclei also provide ascending projections to diverse regions in the forebrain (Törk, 1990) and show high discharge rates in awakening and decreased rates in sleep states (Rasmussen et al., 1984). In addition to modulating cortical neuronal activities dependent on the sleep-wake states, the ascending serotonergic system can sensitize the subcortical circuits associated with autonomic arousal, anxiety and conditioned fear, such as the hypothalamic autonomic control system and the limbic 
system (Lowry, 2002). The stress-induced Fos expression and the diazepaminduced reduction of the Fos expression in the median and dorsal raphe nuclei in the present study suggest the involvement of the ascending serotonergic system in psychosocial stress-associated sensitization of autonomic and emotional circuitries as well as arousal inputs to cortical neurons.

Sensory cortices including the somatosensory, visual, auditory and piriform cortices exhibited robust increases in Fos expression in response to stress, indicating elevated input levels in somatic, visual, auditory and olfactory sensations during exposure to stress. Sensory thalamic nuclei that mediate somatic and auditory sensory signaling to the primary sensory cortices also exhibited Fos expression in response to stress, although it was weaker than the sensory cortices. However, the lateral geniculate nucleus, a thalamic region mediating visual inputs to the primary visual cortex, exhibited relatively high basal Fos expression and did not exhibit a significant increase in Fos expression in response to stress. This observation likely reflects the high basal demand of the visual system in resting conditions.

\section{Emotion systems activated by social stress}

Many limbic regions related to emotion were also classified as type 1 regions, such as hippocampal Ammon's horn, ventral subiculum, septal nuclei, nucleus of the diagonal band, ventral divisions of the BNST, and cortical, medial, lateral and basomedial amygdaloid nuclei. Anatomical studies have revealed that these limbic regions are interconnected and constitute a subcortical network to integrate and process stress signals, which stimulate the hypothalamo-pituitary-adrenocortical axis through the paraventricular hypothalamic nucleus (Herman et al., 2005). Due to the complexity of the network, however, the functional role of each interregional connection in the central stress system is still under investigation. Nonetheless, a recent study using optogenetics in mice showed that glutamatergic and GABAergic projections from the ventral divisions of the BNST to the ventral tegmental area are involved in different emotion-related behaviors: stimulation of the former pathway results in aversive and anxiogenic behavioral phenotypes and the latter produces rewarding and anxiolytic phenotypes (Jennings et al., 2013). We observed social defeat stress-induced Fos expression in the ventral divisions of the BNST and the ventral tegmental area. Although the neurotransmitter contained by the stress- 
activated cells in the ventral divisions of the BNST is unknown, the aversive and anxiety behaviors observed in animals exposed to social stress might be produced by activation of the glutamatergic pathway from the ventral divisions of the BNST to the ventral tegmental area.

The amygdala is involved in the acquisition, storage and expression of fear memory (LeDoux, 2000). Stress-induced increases in Fos expression in amygdaloid subregions in the present study suggest that fear memory was developed following a single social defeat stress episode through the mechanism in the amygdala. Despite the stress-induced activation of the broad area in the amygdala, the central amygdaloid nucleus did not exhibit an increase in Fos expression following social defeat stress. Fos expression in the central amygdaloid nucleus following social defeat stress is inconsistent among studies (Martinez et al., 2002; Fekete et al., 2009). This might be because longer time (> $10 \mathrm{~min}$ ) of exposure to a dominant animal before separation with a partition, as given in the studies showing an increase in Fos expression in this nucleus, can lead to occurrence of attack-caused pain and injuries, which could cause a different expression pattern in the amygdala. We allowed Wistar rats to physically contact with Long-Evans rats for less than 5 min, finding no injury after stress exposure. The present study showed an increase in basal Fos expression in the caudal part of the central amygdaloid nucleus by diazepam injection, consistent with previous reports (Beck and Fibiger, 1995; Salminen et al., 1996; Panhelainen and Korpi, 2012). On the other hand, diazepam reduced stress-induced Fos expression in the medial, lateral, basomedial and cortical amygdaloid nuclei. The central and medial amygdaloid nuclei both provide projections to broad areas in the brain including the brainstem (Hopkins and Holstege, 1978; Canteras et al., 1995). Such diverging efferents from these amygdaloid nuclei could affect global neuronal activities under stress conditions as observed in the forebrain and midbrain following the present social defeat stress, although this study did not cover the pons or medulla. Intriguingly, a lesion study has shown that the medial nucleus is critical to activation of $A 1$ and $A 2$ noradrenergic cells in response to restraint stress, whereas the central nucleus exerts an opposing, inhibitory influence on the stress-induced noradrenergic cell recruitment (Dayas and Day, 2002). The medial nucleus contains both glutamatergic and GABAergic neurons, whereas neurons in the central nucleus are predominantly GABAergic 
(Poulin et al., 2008). Taken together, stress-activated neurons in the medial nucleus could provide glutamatergic excitatory drives to brain regions involved in the expression of stress responses. Diazepam might exert its inhibitory effects on stress responses not only by inhibiting the excitatory drives from the medial nucleus, but also by enhancing GABAergic drives from the central part to various stress-related brain regions.

The habenula is involved in behavioral responses to stress (Hikosaka, 2010). We observed social defeat stress-induced Fos expression in the medial and lateral habenular nuclei. Immobilization and open field stress also induce Fos expression in the lateral habenular nucleus (Wirtshafter et al., 1994). It has been proposed that habenular neurons, upon receiving stress-related signals from limbic regions, inhibit raphe serotonergic neurons as well as nigrotegmental dopaminergic neurons, resulting in a general suppression of body movement (Hikosaka, 2010). The distribution of Fos-IR cells in the lateral habenular nucleus following social defeat stress was relatively confined to its medial part. Neurons in this part receive projections from limbic regions including the septum, diagonal band of Broca, and medial frontal cortex (Herkenham and Nauta, 1977). Therefore, the activation of the lateral habenular neurons by stress signals from these limbic regions may be involved in the motor suppression occurring under exposure to stress. The stressinduced Fos expression in the lateral habenular nucleus was inhibited by diazepam, whereas this drug further increased that in the medial habenular nucleus. Although the stress circuits involving the medial habenular nucleus are mostly unknown, a recent study suggested that activation of neurons in its ventral part, which occupies a major area of the medial habenular nucleus, leads to anxiety-related behaviors (Yamaguchi et al., 2013). Activation of medial habenular neurons by diazepam as seen in the present study may lead to an increase in anxiety, which might cause paradoxical effects of this drug, such as self-aggressive behaviors in humans (Berman et al., 2005).

\section{CONCLUSION}

The distribution of Fos-IR cells shown in the present study indicates that social defeat stress recruits neurons in broad forebrain and midbrain regions. Diazepaminduced strong, selective inhibition of the stress-induced neuronal activation was observed in many of these brain regions and suggests that neurons in these regions 
are involved in perception of stressors, processing of stress and emotional signals, or output of behavioral and autonomic (including neuroendocrine) motor commands to cope with stressors. PSH is one of fundamental autonomic responses to stress and employs sympathetic thermogenesis in BAT through activation of sympathetic premotor neurons in the rostral medullary raphe region, similar to the development of fever. However, evidence from the present and previous studies dissociates the mechanisms for triggering $\mathrm{PSH}$ and fever, although $\mathrm{PSH}$ and fever likely share the sympathetic outflow pathway through the dorsomedial hypothalamus and the rostral medullary raphe region. Fos expression in the paraventricular hypothalamic nucleus indicates that social defeat stress activates efferent drives for the hypothalamopituitary-adrenocortical neuroendocrine axis and for autonomic outflows, which seem to show different sensitivity to diazepam. Increases in arousal and awareness necessary for processing incoming information during exposure to stressors are likely mediated by activated cortical inputs from the midline and intralaminar thalamic nuclei. The elevated arousal level during stress may be maintained by stressactivated histaminergic, serotonergic and orexinergic neurons through their innervation of broad areas in the forebrain. The social defeat stress-induced activation of neurons in various limbic and related regions, such as the amygdala, septum, BNST, ventral tegmental area and hebenula, seems to be involved in the production of negative emotion, such as anxiety and fear, associated with aversive stress episodes. Diazepam's excitatory effects on the central amygdaloid nucleus and medial habenular nucleus are curious and might be related with its diverse inhibitory pharmacological effects and paradoxical side effects, respectively. The present functional mapping of neurons exhibiting diazepam-sensitive, stress-induced activation would be helpful for future physiological attempts to understand the central circuit mechanisms for the development of acute autonomic, emotional and behavioral responses to psychosocial stress as well as the etiology of various disorders and illnesses caused by chronic stress, such as psychogenic fever and depression. 


\section{CONFLICT OF INTEREST}

Authors declare no conflict of interest.

\section{CONTRIBUTIONS}

Study concept and design: T.O., H.H., K.N. Acquisition of physiological data: L.B., T.O. Acquisition of immunohistochemical data: L.B., Y.N., K.N. Analysis of data: L.B., K.N. Interpretation of data: L.B., T.O., K.N. Drafting the manuscript: L.B., T.O., K.N. Critical revision of the manuscript for important intellectual content: L.B., T.O., Y.N., H.H., N.S., K.N.

\section{Acknowledgements}

Authors thank Tetsuya Hiramoto and Chika Tanizawa for technical assistance and Yoshie Nakagawa for assistance with manuscript preparation. This study was supported by the Funding Program for Next Generation World-Leading Researchers from the Japan Society for the Promotion of Science (LS070 to K.N.), by a Special Coordination Fund for Promoting Science and Technology (to K.N.) and Grants-inAid for Scientific Research (23390189 to T.O., 23790271 and 26860159 to Y.N., 22590671 to H.H., and 21890114, 22689007, 26118508 and 26713009 to K.N.) from the Ministry of Education, Culture, Sports, Science and Technology of Japan, and by grants from the Nakajima Foundation, Takeda Science Foundation and Kowa Life Science Foundation (to K.N.). 


\section{REFERENCES}

Ashton H (1994) Guidelines for the rational use of benzodiazepines. When and what to use. Drugs 48:25-40.

Beck CHM, Fibiger HC (1995) Conditioned fear-induced changes in behavior and in the expression of the immediate early gene c-fos: with and without diazepam pretreatment. J Neurosci 15:709-720.

Berman ME, Jones GD, McCloskey MS (2005) The effects of diazepam on human self-aggressive behavior. Psychopharmacology (Berl) 178:100-106.

Berthoud HR, Patterson LM, Sutton GM, Morrison C, Zheng H (2005) Orexin inputs to caudal raphé neurons involved in thermal, cardiovascular, and gastrointestinal regulation. Histochem Cell Biol 123:147-156.

Bizzi A, Ricci MR, Veneroni E, Amato M, Garattini S (1984) Benzodiazepine receptor antagonists reverse the effect of diazepam on plasma corticosterone in stressed rats. J Pharm Pharmacol 36:134-135.

Björkqvist K (2001) Social defeat as a stressor in humans. Physiol Behav 73:435442.

Canteras NS, Simerly RB, Swanson LW (1995) Organization of projections from the medial nucleus of the amygdala: a PHAL study in the rat. J Comp Neurol 360:213-245.

Chung KKK, Martinez M, Herbert J (1999) Central serotonin depletion modulates the behavioural, endocrine and physiological responses to repeated social stress and subsequent $c$-fos expression in the brains of male rats. Neuroscience 92:613-625.

Chung KKK, Martinez M, Herbert J (2000) c-fos expression, behavioural, endocrine and autonomic responses to acute social stress in male rats after chronic restraint: modulation by serotonin. Neuroscience 95:453-463. 
Dayas CV, Day TA (2002) Opposing roles for medial and central amygdala in the initiation of noradrenergic cell responses to a psychological stressor. Eur $\mathrm{J}$ Neurosci 15:1712-1718.

de Kloet ER, Joëls M, Holsboer F (2005) Stress and the brain: from adaptation to disease. Nat Rev Neurosci 6:463-475.

Ebner K, Wotjak CT, Landgraf R, Engelmann M (2000) A single social defeat experience selectively stimulates the release of oxytocin, but not vasopressin, within the septal brain area of male rats. Brain Res 872:87-92.

Eisenberg RM (1993) Sound vibration, a non-invasive stress: antagonism by diazepam. Psychopharmacology (Berl) 110:467-470.

Elmquist JK, Scammell TE, Jacobson CD, Saper CB (1996) Distribution of Fos-like immunoreactivity in the rat brain following intravenous lipopolysaccharide administration. J Comp Neurol 371:85-103.

Fekete ÉM, Zhao Y, Li C, Sabino V, Vale WW, Zorrilla EP (2009) Social defeat stress activates medial amygdala cells that express type 2 corticotropinreleasing factor receptor mRNA. Neuroscience 162:5-13.

Ferguson AV, Latchford KJ, Samson WK (2008) The paraventricular nucleus of the hypothalamus - a potential target for integrative treatment of autonomic dysfunction. Expert Opin Ther Targets 12:717-727.

Frank E, Salchner P, Aldag JM, Salomé N, Singewald N, Landgraf R, Wigger A (2006) Genetic predisposition to anxiety-related behavior determines coping style, neuroendocrine responses, and neuronal activation during social defeat. Behav Neurosci 120:60-71.

Groenink L, van der Gugten J, Zethof TJJ, van der Heyden JAM, Olivier B (1996) Neuroendocrine effects of diazepam and flesinoxan in the stress-induced hyperthermia test in mice. Pharmacol Biochem Behav 54:249-254. 
Herkenham M, Nauta WJH (1977) Afferent connections of the habenular nuclei in the rat. A horseradish peroxidase study, with a note on the fiber-of-passage problem. J Comp Neurol 173:123-145.

Herman JP, Mueller NK, Figueiredo H (2004) Role of GABA and glutamate circuitry in hypothalamo-pituitary-adrenocortical stress integration. Ann N Y Acad Sci 1018:35-45.

Herman JP, Ostrander MM, Mueller NK, Figueiredo H (2005) Limbic system mechanisms of stress regulation: hypothalamo-pituitary-adrenocortical axis. Prog Neuropsychopharmacol Biol Psychiatry 29:1201-1213.

Hikosaka O (2010) The habenula: from stress evasion to value-based decisionmaking. Nat Rev Neurosci 11:503-513.

Hiramoto T, Oka T, Yoshihara K, Kubo C (2009) Pyrogenic cytokines did not mediate a stress interview-induced hyperthermic response in a patient with psychogenic fever: a case report. Psychosom Med 71:932-936.

Hopkins DA, Holstege G (1978) Amygdaloid projections to the mesencephalon, pons and medulla oblongata in the cat. Exp Brain Res 32:529-547.

Hosoya Y, Ito R, Kohno K (1987) The topographical organization of neurons in the dorsal hypothalamic area that project to the spinal cord or to the nucleus raphé pallidus in the rat. Exp Brain Res 66:500-506.

Huhman KL (2006) Social conflict models: can they inform us about human psychopathology? Horm Behav 50:640-646.

Jennings JH, Sparta DR, Stamatakis AM, Ung RL, Pleil KE, Kash TL, Stuber GD (2013) Distinct extended amygdala circuits for divergent motivational states. Nature 496:224-228.

Kalman BA, Kim PJ, Cole MA, Chi MS, Spencer RL (1997) Diazepam attenuation of restraint stress-induced corticosterone levels is enhanced by prior exposure to repeated restraint. Psychoneuroendocrinology 22:349-360. 
Kaneko T (2013) Local connections of excitatory neurons in motor-associated cortical areas of the rat. Front Neural Circuits 7:75.

Knobloch HS, Charlet A, Hoffmann LC, Eliava M, Khrulev S, Cetin AH, Osten P, Schwarz MK, Seeburg PH, Stoop R, Grinevich V (2012) Evoked axonal oxytocin release in the central amygdala attenuates fear response. Neuron 73:553-566.

Kollack-Walker S, Newman SW (1995) Mating and agonistic behavior produce different patterns of Fos immunolabeling in the male Syrian hamster brain. Neuroscience 66:721-736.

Kollack-Walker S, Watson SJ, Akil H (1997) Social stress in hamsters: defeat activates specific neurocircuits within the brain. J Neurosci 17:8842-8855.

Lazarus M, Yoshida K, Coppari R, Bass CE, Mochizuki T, Lowell BB, Saper CB (2007) EP3 prostaglandin receptors in the median preoptic nucleus are critical for fever responses. Nat Neurosci 10: 1131-1133.

Lecci A, Borsini F, Volterra G, Meli A (1990) Pharmacological validation of a novel animal model of anticipatory anxiety in mice. Psychopharmacology (Berl) 101:255-261.

LeDoux JE (2000) Emotion circuits in the brain. Annu Rev Neurosci. 23:155-184.

Lkhagvasuren B, Nakamura Y, Oka T, Sudo N, Nakamura K (2011) Social defeat stress induces hyperthermia through activation of thermoregulatory sympathetic premotor neurons in the medullary raphe region. Eur $\mathrm{J}$ Neurosci 34:1442-1452.

Lowry CA (2002) Functional subsets of serotonergic neurones: implications for control of the hypothalamic-pituitary-adrenal axis. J Neuroendocrinol 14:911923.

Luong LNL, Carrive P (2012) Orexin microinjection in the medullary raphe increases heart rate and arterial pressure but does not reduce tail skin blood flow in the awake rat. Neuroscience 202:209-217. 
Madden CJ, Morrison SF (2004) Excitatory amino acid receptors in the dorsomedial hypothalamus mediate prostaglandin-evoked thermogenesis in brown adipose tissue. Am J Physiol Regul Integr Comp Physiol 286:R320-R325.

Martinez M, Calvo-Torrent A, Herbert J (2002) Mapping brain response to social stress in rodents with c-fos expression: a review. Stress 5:3-13.

Martinez M, Phillips PJ, Herbert J. (1998) Adaptation in patterns of c-fos expression in the brain associated with exposure to either single or repeated social stress in male rats. Eur J Neurosci 10:20-33.

Matsuda S, Peng H, Yoshimura H, Wen TC, Fukuda T, Sakanaka M (1996) Persistent c-fos expression in the brains of mice with chronic social stress. Neurosci Res 26:157-170.

Meister B (1993) Gene expression and chemical diversity in hypothalamic neurosecretory neurons. Mol Neurobiol 7:87-110.

Miczek KA, Nikulina E, Kream RM, Carter G, Espejo EF (1999) Behavioral sensitization to cocaine after a brief social defeat stress: $c$-fos expression in the PAG. Psychopharmacology 141:225-234.

Miczek KA, Thompson ML, Shuster L (1982) Opioid-like analgesia in defeated mice. Science 215:1520-1522.

Morrison SF, Nakamura K (2011) Central neural pathways for thermoregulation. Front Biosci. 16:74-104.

Nakamura K (2011) Central circuitries for body temperature regulation and fever. Am J Physiol Regul Integr Comp Physiol. 301:R1207-R1228.

Nakamura K, Kaneko T, Yamashita Y, Hasegawa H, Katoh H, Ichikawa A, Negishi M (1999) Immunocytochemical localization of prostaglandin EP3 receptor in the rat hypothalamus. Neurosci Lett 260: 117-120.

Nakamura K, Kaneko T, Yamashita Y, Hasegawa H, Katoh H, Negishi M (2000) Immunohistochemical localization of prostaglandin EP3 receptor in the rat nervous system. J Comp Neurol 421: 543-569. 
Nakamura K, Matsumura K, Hübschle T, Nakamura Y, Hioki H, Fujiyama F, Boldogköi Z, König M, Thiel HJ, Gerstberger R, Kobayashi S, Kaneko T (2004) Identification of sympathetic premotor neurons in medullary raphe regions mediating fever and other thermoregulatory functions. J Neurosci 24:5370-5380.

Nakamura K, Matsumura K, Kaneko T, Kobayashi S, Katoh H, Negishi M (2002) The rostral raphe pallidus nucleus mediates pyrogenic transmission from the preoptic area. J Neurosci 22:4600-4610.

Nakamura K, Morrison SF (2007) Central efferent pathways mediating skin coolingevoked sympathetic thermogenesis in brown adipose tissue. Am J Physiol Regul Integr Comp Physiol 292:R127-R136.

Nakamura K, Morrison SF (2008a) A thermosensory pathway that controls body temperature. Nat Neurosci 11: 62-71.

Nakamura K, Morrison SF (2008b) Preoptic mechanism for cold-defensive responses to skin cooling. J Physiol 586: 2611-2620.

Nakamura K, Morrison SF (2010) A thermosensory pathway mediating heat-defense responses. Proc Natl Acad Sci USA 107: 8848-8853.

Nakamura Y, Nakamura K, Matsumura K, Kobayashi S, Kaneko T, Morrison SF (2005) Direct pyrogenic input from prostaglandin EP3 receptor-expressing preoptic neurons to the dorsomedial hypothalamus. Eur J Neurosci 22:31373146.

Oka T, Oka K (2012) Mechanisms of psychogenic fever. Adv Neuroimmune Biol 3:317.

Oka T, Oka K, Hori T (2001) Mechanisms and mediators of psychological stressinduced rise in core temperature. Psychosom Med 63:476-486.

Oka T, Oka K, Kobayashi T, Sugimoto Y, Ichikawa A, Ushikubi F, Narumiya S, Saper CB (2003) Characteristics of thermoregulatory and febrile responses in mice deficient in prostaglandin EP1 and EP3 receptors. J Physiol 551:945-954. 
Osaka T (2004) Cold-induced thermogenesis mediated by GABA in the preoptic area of anesthetized rats. Am J Physiol Regul Integr Comp Physiol 287: R306R313.

Panhelainen AE, Korpi ER (2012) Evidence for a role of inhibition of orexinergic neurons in the anxiolytic and sedative effects of diazepam: a c-Fos study. Pharmacol Biochem Behav 101:115-124.

Paxinos G, Watson C (1998) The Rat Brain in Stereotaxic Coordinates, 4th edn. San Diego: Academic Press.

Peyron C, Tighe DK, van den Pol AN, de Lecea L, Heller HC, Sutcliffe JG, Kilduff TS (1998) Neurons containing hypocretin (orexin) project to multiple neuronal systems. J Neurosci 18:9996-10015.

Poulin JF, Castonguay-Lebel Z, Laforest S, Drolet G (2008) Enkephalin coexpression with classic neurotransmitters in the amygdaloid complex of the rat. J Comp Neurol 506:943-959.

Prince CR, Collins C, Anisman H (1986) Stressor-provoked response patterns in a swim task: modification by diazepam. Pharmacol Biochem Behav 24:323-328.

Radley JJ, Arias CM, Sawchenko PE (2006) Regional differentiation of the medial prefrontal cortex in regulating adaptive responses to acute emotional stress. $J$ Neurosci 26:12967-12976.

Rasmussen K, Heym J, Jacobs BL (1984) Activity of serotonin-containing neurons in nucleus centralis superior of freely moving cats. Exp Neurol 83:302-317.

Sagar SM, Sharp FR, Curran T (1988) Expression of c-fos protein in brain: metabolic mapping at the cellular level. Science 240:1328-1331.

Salminen O, Lahtinen S, Ahtee L (1996) Expression of Fos protein in various rat brain areas following acute nicotine and diazepam. Pharmacol Biochem Behav 54:241-248. 
Samuels BC, Zaretsky DV, DiMicco JA (2004) Dorsomedial hypothalamic sites where disinhibition evokes tachycardia correlate with location of rapheprojecting neurons. Am J Physiol Regul Integr Comp Physiol 287:R472-R478.

Sawchenko PE, Brown ER, Chan RKW, Ericsson A, Li HY, Roland BL, Kovács KJ (1996) The paraventricular nucleus of the hypothalamus and the functional neuroanatomy of visceromotor responses to stress. Prog Brain Res 107:201222.

Scammell TE, Elmquist JK, Griffin JD, Saper CB (1996) Ventromedial preoptic prostaglandin E2 activates fever-producing autonomic pathways. J Neurosci $16: 6246-6254$.

Shannon HE, Herling S (1983) Discriminative stimulus effects of diazepam in rats: evidence for a maximal effect. J Pharmacol Exp Ther 227:160-166.

Sherin JE, Elmquist JK, Torrealba F, Saper CB (1998) Innervation of histaminergic tuberomammillary neurons by GABAergic and galaninergic neurons in the ventrolateral preoptic nucleus of the rat. J Neurosci. 18:4705-4721.

Sparta DR, Jennings JH, Ung RL, Stuber GD (2013) Optogenetic strategies to investigate neural circuitry engaged by stress. Behav Brain Res 255:19-25.

Stotz-Potter EH, Morin SM, DiMicco JA (1996a) Effect of microinjection of muscimol into the dorsomedial or paraventricular hypothalamic nucleus on air stressinduced neuroendocrine and cardiovascular changes in rats. Brain Res 742:219-224.

Stotz-Potter EH, Willis LR, DiMicco JA (1996b) Muscimol acts in dorsomedial but not paraventricular hypothalamic nucleus to suppress cardiovascular effects of stress. J Neurosci 16:1173-1179.

Swanson LW, Sawchenko PE (1980) Paraventricular nucleus: a site for the integration of neuroendocrine and autonomic mechanisms. Neuroendocrinology 31:410-417. 
Szymusiak R, Alam N, Steininger TL, McGinty D (1998) Sleep-waking discharge patterns of ventrolateral preoptic/anterior hypothalamic neurons in rats. Brain Res 803:178-188.

Tanaka M, McKinley MJ, McAllen RM (2011) Preoptic-Raphé Connections for Thermoregulatory Vasomotor Control. J Neurosci 31: 5078-5088.

Thakkar MM (2011) Histamine in the regulation of wakefulness. Sleep Med Rev $15: 65-74$.

Törk I (1990) Anatomy of the serotonergic system. Ann N Y Acad Sci 600:9-35.

Tornatzky W, Miczek KA (1993) Long-term impairment of autonomic circadian rhythms after brief intermittent social stress. Physiol Behav 53:983-993.

Tupone D, Madden CJ, Cano G, Morrison SF (2011) An orexinergic projection from perifornical hypothalamus to raphe pallidus increases rat brown adipose tissue thermogenesis. J Neurosci. 31:15944-15955.

Van der Werf YD, Witter MP, Groenewegen HJ (2002) The intralaminar and midline nuclei of the thalamus. Anatomical and functional evidence for participation in processes of arousal and awareness. Brain Res Rev 39:107-140.

Vinkers $\mathrm{CH}$, Groenink L, van Bogaert MJV, Westphal KGC, Kalkman CJ, van Oorschot R, Oosting RS, Olivier B, Korte SM (2009) Stress-induced hyperthermia and infection-induced fever: two of a kind? Physiol Behav 98: 37-43.

Wirtshafter D, Asin KE, Pitzer MR (1994) Dopamine agonists and stress produce different patterns of Fos-like immunoreactivity in the lateral habenula. Brain Res 633:21-26.

Wotjak CT, Kubota M, Liebsch G, Montkowski A, Holsboer F, Neumann I, Landgraf R (1996) Release of vasopressin within the rat paraventricular nucleus in response to emotional stress: a novel mechanism of regulating adrenocorticotropic hormone secretion? J Neurosci 16:7725-7732. 
Yamagata K, Matsumura K, Inoue W, Shiraki T, Suzuki K, Yasuda S, Sugiura H, Cao C, Watanabe Y, Kobayashi S (2001) Coexpression of microsomal-type prostaglandin E synthase with cyclooxygenase-2 in brain endothelial cells of rats during endotoxin-induced fever. J Neurosci 21: 2669-2677.

Yamaguchi T, Danjo T, Pastan I, Hikida T, Nakanishi S (2013) Distinct roles of segregated transmission of the septo-habenular pathway in anxiety and fear. Neuron 78:537-544.

Zaretsky DV, Hunt JL, Zaretskaia MV DiMicco JA (2006) Microinjection of prostaglandin E2 and muscimol into the preoptic area in conscious rats: comparison of effects on plasma adrenocorticotrophic hormone (ACTH), body temperature, locomotor activity, and cardiovascular function. Neurosci Lett 397: 291-296.

Zethof TJJ, Van der Heyden JAM, Tolboom JTBM, Olivier B (1995) Stress-induced hyperthermia as a putative anxiety model. Eur J Pharmacol 294:125-135.

Zhang W, Sunanaga J, Takahashi Y, Mori T, Sakurai T, Kanmura Y, Kuwaki T (2010) Orexin neurons are indispensable for stress-induced thermogenesis in mice. J Physiol 588:4117-4129. 


\section{Figures}

A

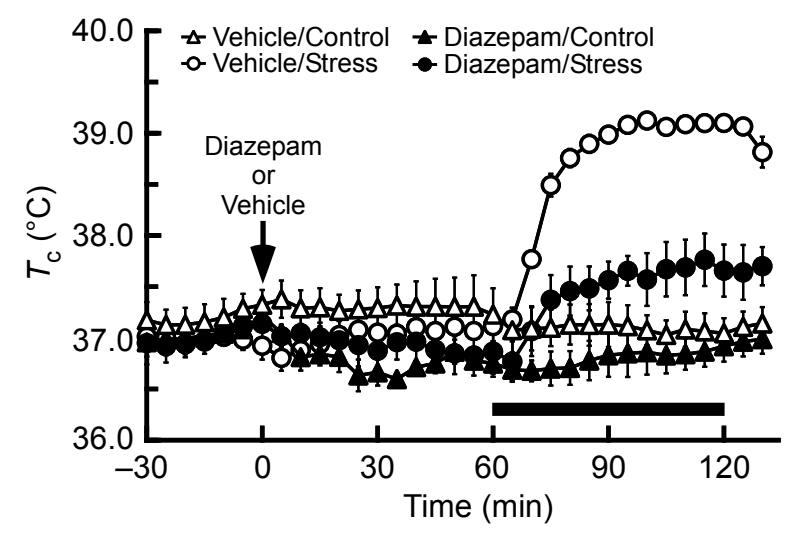

B

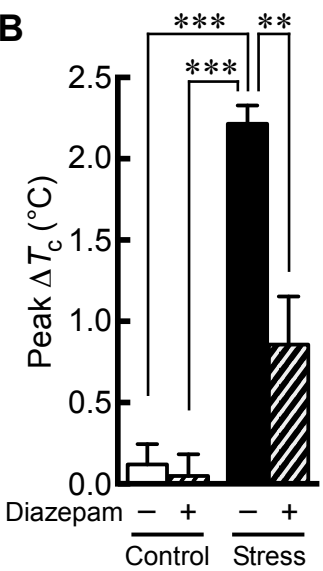

Fig. 1. Effect of diazepam on social defeat stress-induced increase in body core temperature $\left(T_{c}\right)$. (A) Abdominal temperature was measured in rats $(n=4 \mathrm{per}$ group) that received an i.p. injection of diazepam (filled symbols) or vehicle (open symbols) at the time point indicated by the arrow and were subsequently exposed to social defeat stress (circles) or left undisturbed (triangles) during the period indicated by the horizontal bar. (B) Peak changes in $T_{c}$ during the stress or control period from the pre-injection baseline values (peak $\Delta T_{c}$ ) in the four groups ( $n=4$ per group). ${ }^{* * *} P<0.001,{ }^{* *} P<0.01$, one-way ANOVA. 


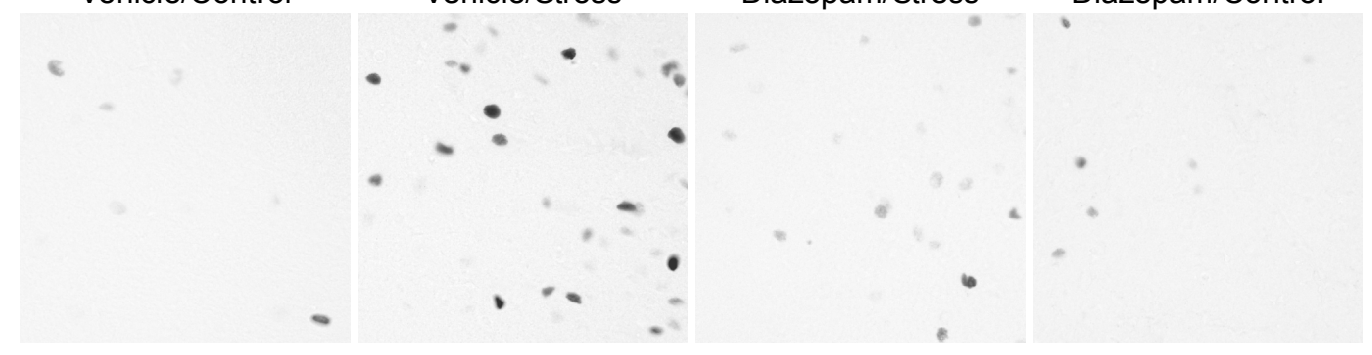

Lkhagvasuren et al., Neuroscience

Figure 2. Two column width

Fig. 2. Representative images used for counting Fos-immunoreactive (IR) cells in the dorsomedial hypothalamic nucleus. Fos-IR cells in $200-\mu \mathrm{m}$ squares from the four experimental groups are shown. The numbers of Fos-IR cells that we counted in these images are 6 (Vehicle/Control), 35 (Vehicle/Stress), 17 (Diazepam/Stress) and 7 (Diazepam/Control) cells. For the detailed procedure of cell counting, see Materials and methods. 
$\mathrm{DH}$

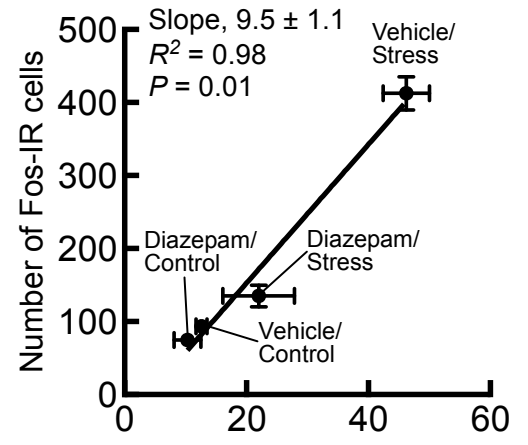

Fos-IR cell density (cells / $0.04 \mathrm{~mm}^{2}$ )
$\mathrm{DMH}$

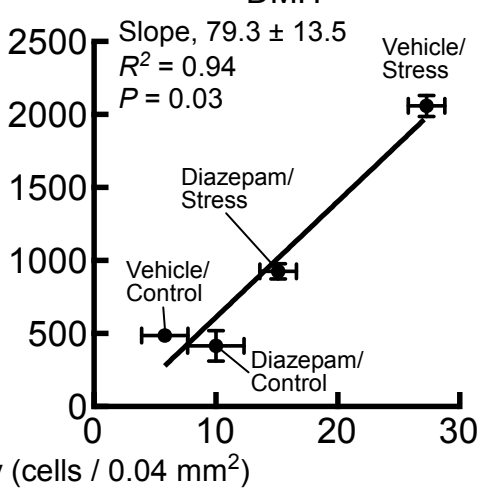

Lkhagvasuren et al., Neuroscience

Figure 3. One column width

Fig. 3. Correlation between the density and number of Fos-IR cells in the dorsal hypothalamic area (DH) and dorsomedial hypothalamic nucleus (DMH). Mean values ( \pm S.E.M.) from the four experimental groups are plotted ( $n=4$ per group). Linear regression analysis indicates a significant correlation $(P<0.05)$ between the density and number of Fos-IR cells in both regions. 


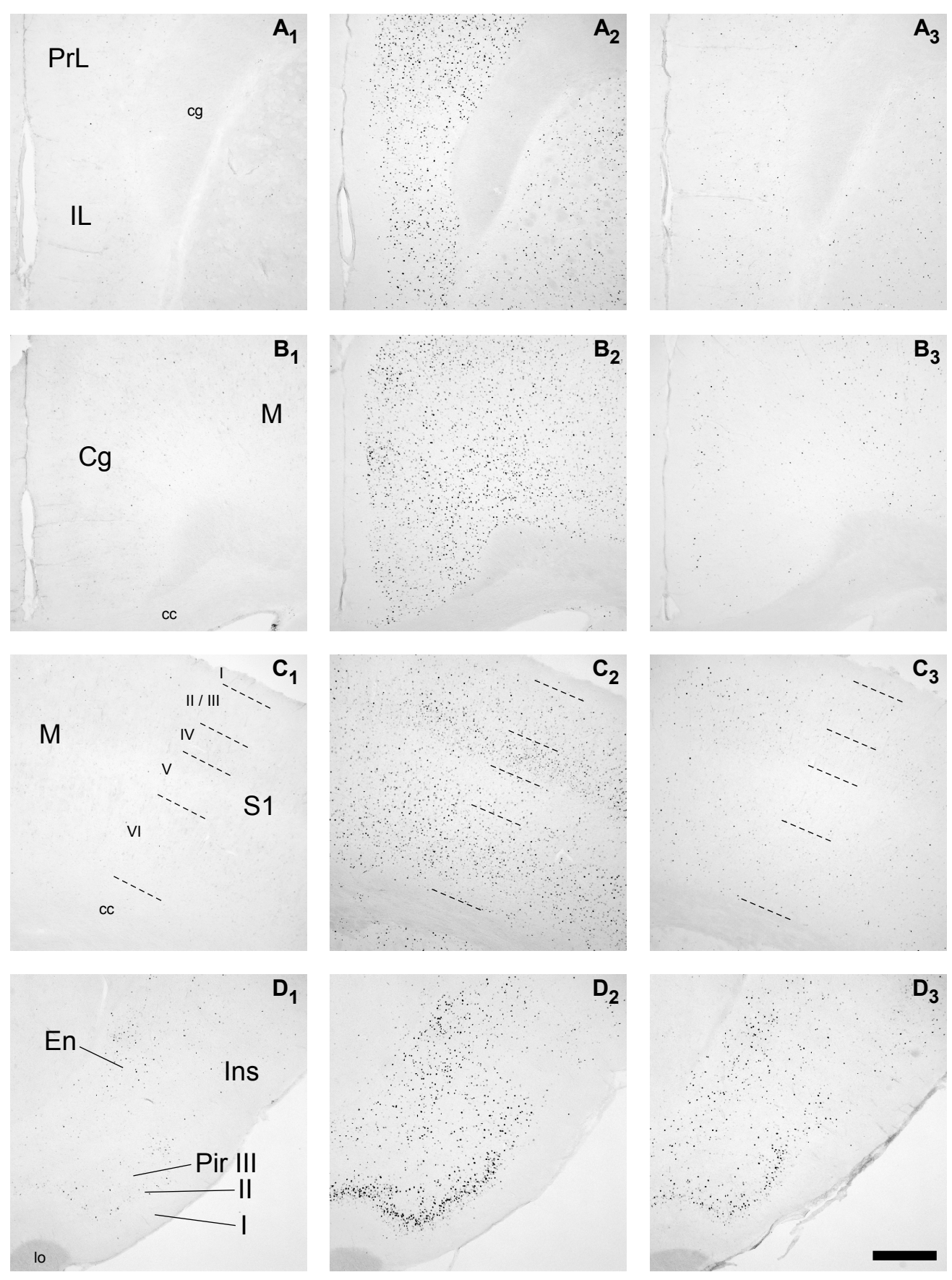

Lkhagvasuren et al., Neuroscience Figure 4. Two column width

Fig. 4. Distribution of Fos-IR cells in the cerebral cortex. $\left(A_{1}-A_{3}\right)$ Prelimbic (PrL) and infralimbic (IL) cortices. ( $\left(B_{1}-B_{3}\right)$ Cingulate cortex $(C g)$. $\left(C_{1}-C_{3}\right)$ Motor $(M)$ and primary somatosensory (S1) cortices. Broken lines indicate cortical layer boundaries. $\left(D_{1}-D_{3}\right)$ Piriform (Pir) and insular (Ins) cortices and endopiriform nucleus (En). Photomicrographic images were taken from Vehicle/Control $\left(A_{1}-D_{1}\right)$, Vehicle/Stress 
$\left(A_{2}-D_{2}\right)$ and Diazepam/Stress $\left(A_{3}-D_{3}\right)$ groups. For other abbreviations, see the abbreviation list. Scale bar: $500 \mu \mathrm{m}$. 

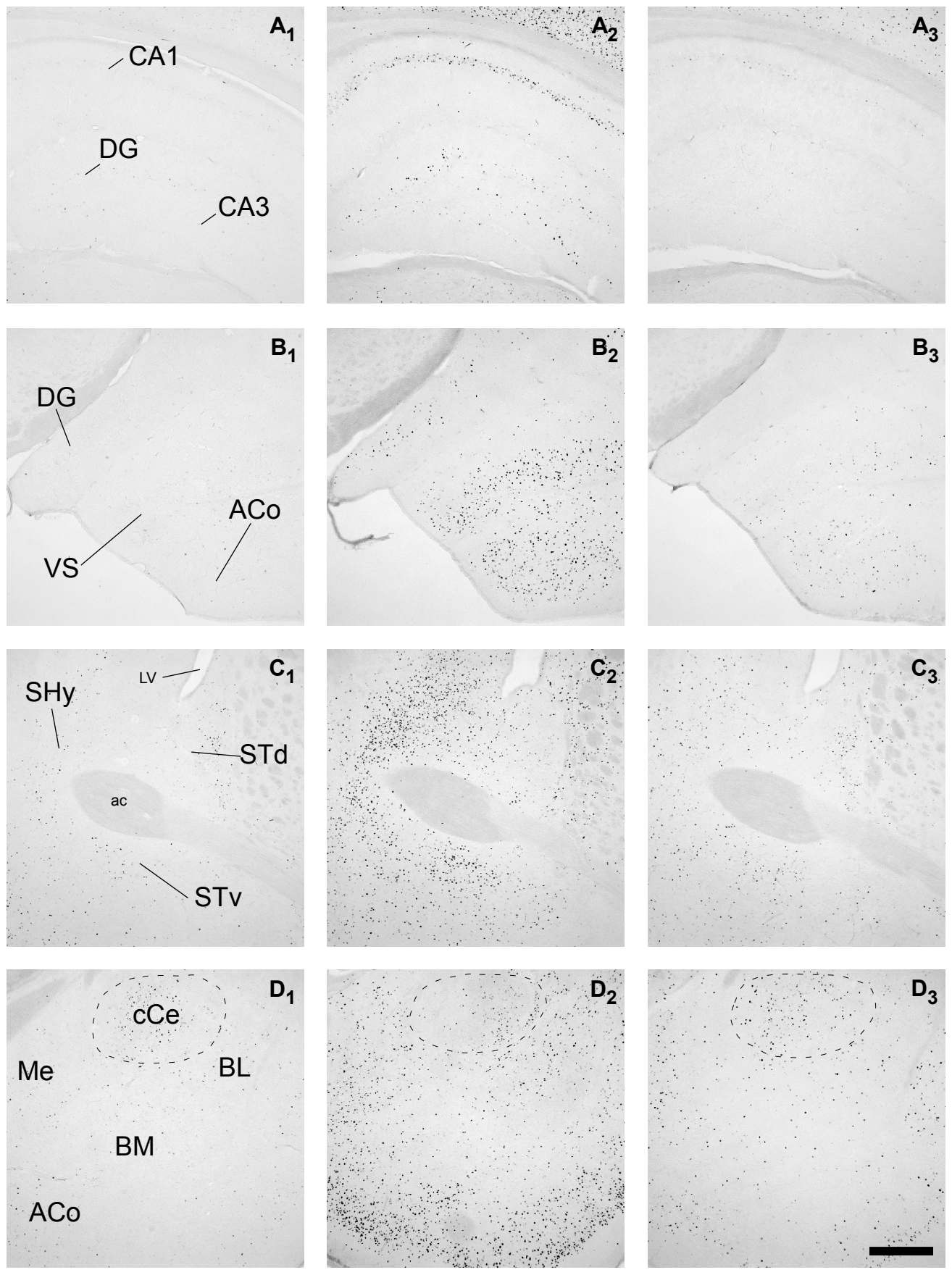

Lkhagvasuren et al., Neuroscience

Figure 5. Two column width

Fig. 5. Distribution of Fos-IR cells in the hippocampal formation (dorsal, $A_{1}-A_{3}$; ventral, $\left.B_{1}-B_{3}\right)$, septal region $\left(C_{1}-C_{3}\right)$ and amygdala $\left(D_{1}-D_{3}\right)$. Broken lines in $D_{1}-D_{3}$ delineate the caudal part of the central amygdaloid nucleus $(\mathrm{cCe})$. Photomicrographic images were taken from Vehicle/Control $\left(A_{1}-D_{1}\right)$, Vehicle/Stress 
$\left(A_{2}-D_{2}\right)$ and Diazepam/Stress $\left(A_{3}-D_{3}\right)$ groups. For other abbreviations, see the abbreviation list. Scale bar: $500 \mu \mathrm{m}$. 

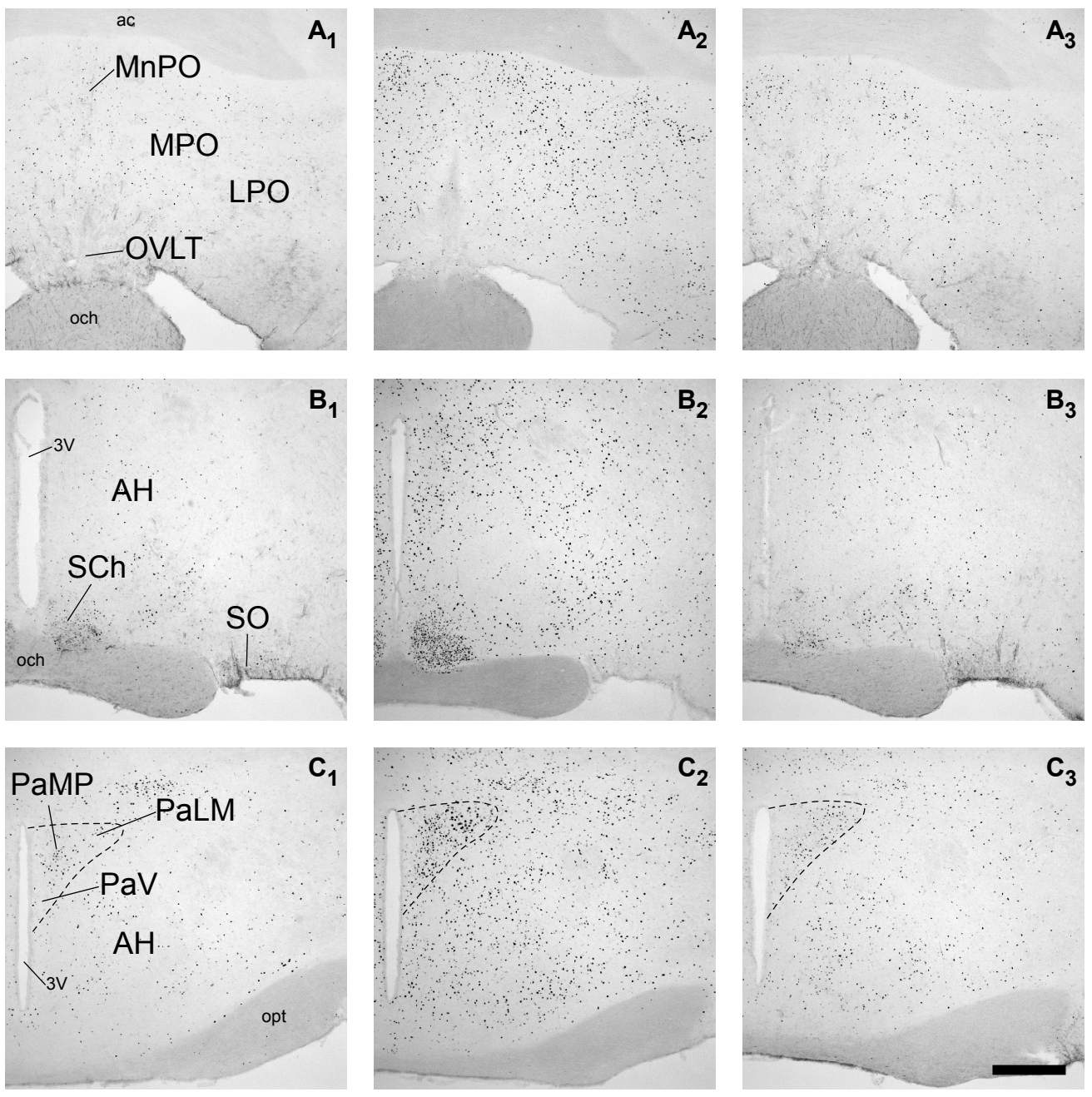

Lkhagvasuren et al., Neuroscience

Figure 6. Two column width

Fig. 6. Distribution of Fos-IR cells in the preoptic area and rostral hypothalamus. $\left(A_{1}-A_{3}\right)$ Preoptic area. $\left(B_{1}-B_{3}\right)$ Rostral hypothalamic area including the suprachiasmatic nucleus (SCh) and supraoptic nucleus (SO). ( $\left(\mathrm{C}_{1}-\mathrm{C}_{3}\right)$ Rostral hypothalamic area including the paraventricular hypothalamic nucleus. Photomicrographic images were taken from Vehicle/Control $\left(A_{1}-C_{1}\right)$, Vehicle/Stress $\left(A_{2}-C_{2}\right)$ and Diazepam/Stress $\left(A_{3}-C_{3}\right)$ groups. For other abbreviations, see the abbreviation list. Scale bar: $500 \mu \mathrm{m}$. 

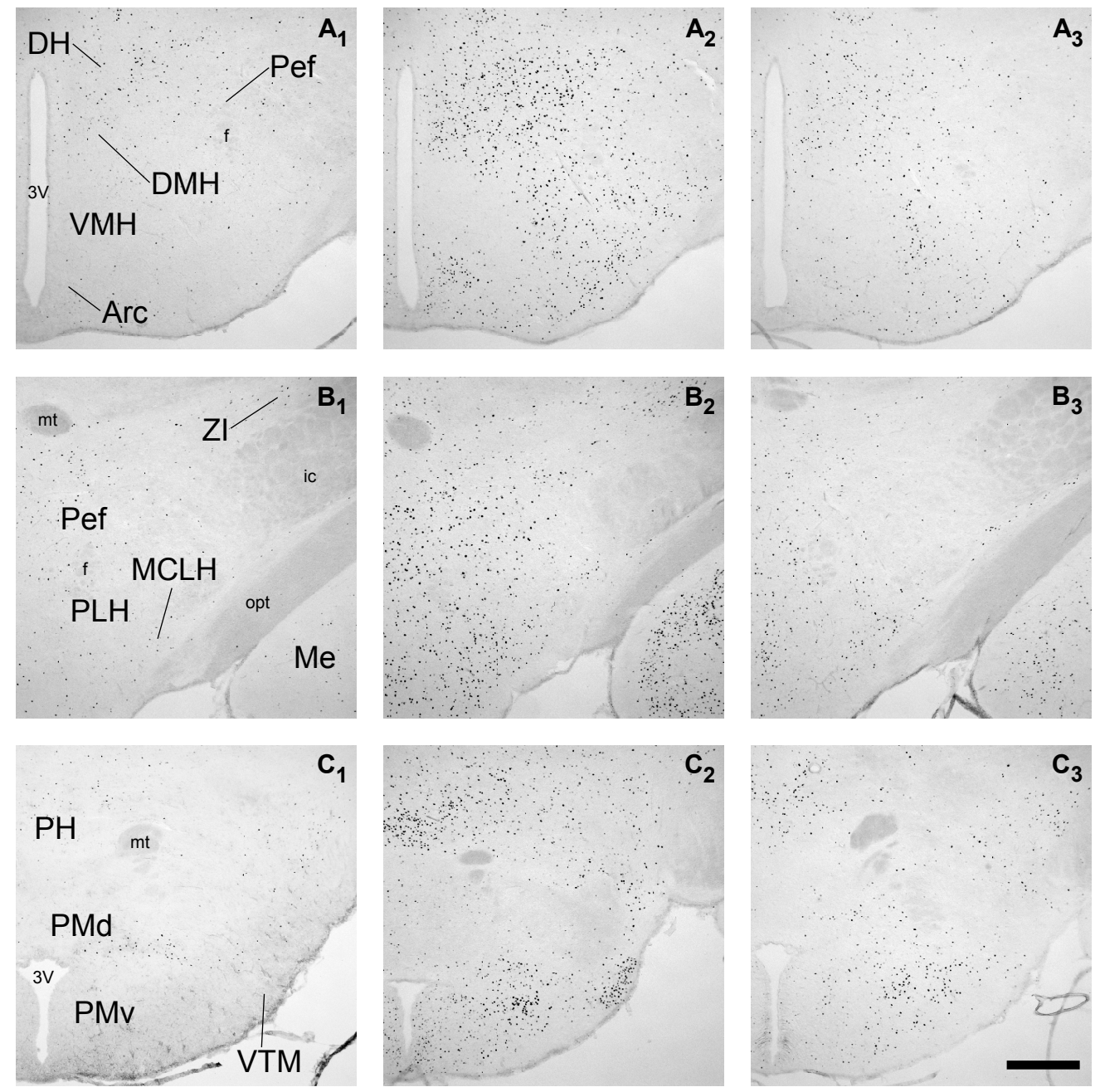

Lkhagvasuren et al., Neuroscience Figure 7 Two column width

Fig. 7. Distribution of Fos-IR cells in caudal hypothalamus. $\left(A_{1}-A_{3}\right)$ Caudal hypothalamic area including the $\mathrm{DH}, \mathrm{DMH}$, ventromedial hypothalamic nucleus $(\mathrm{VMH})$ and perifornical nucleus (Pef). ( $\left.\mathrm{B}_{1}-\mathrm{B}_{3}\right)$ Lateral hypothalamus. $\left(\mathrm{C}_{1}-\mathrm{C}_{3}\right)$ Mammillary body. Photomicrographic images were taken from Vehicle/Control $\left(A_{1}-\right.$ $\left.C_{1}\right)$, Vehicle/Stress $\left(A_{2}-C_{2}\right)$ and Diazepam/Stress $\left(A_{3}-C_{3}\right)$ groups. For other abbreviations, see the abbreviation list. Scale bar: $500 \mu \mathrm{m}$. 

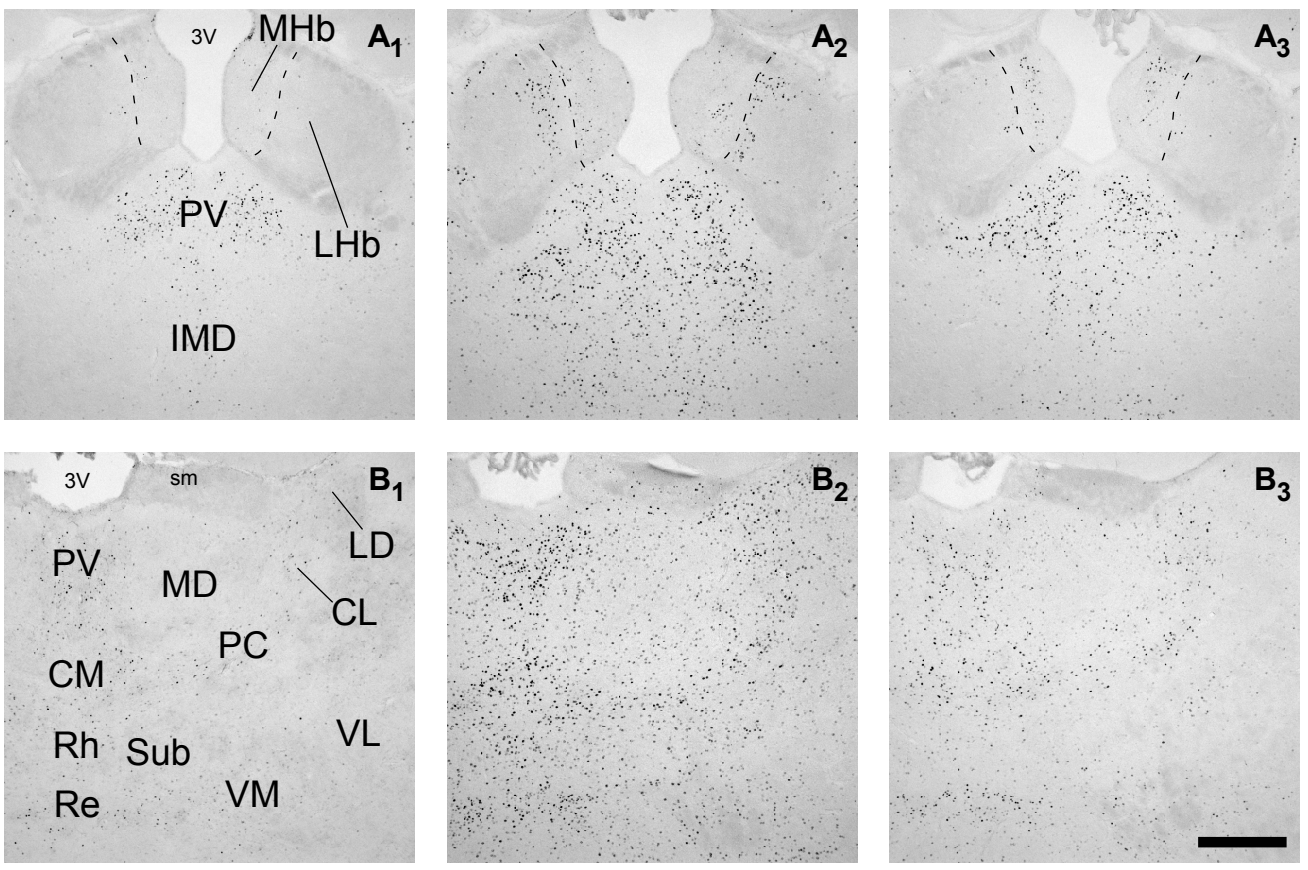

Lkhagvasuren et al., Neuroscience

Figure 8. Two column width

Fig. 8. Distribution of Fos-IR cells in the habenula and thalamus. $\left(A_{1}-A_{3}\right)$ Habenula and paraventricular thalamic nucleus (PV). Broken lines indicate the boundary between the medial $(\mathrm{MHb})$ and lateral $(\mathrm{LHb})$ habenular nuclei. $\left(\mathrm{B}_{1}-\mathrm{B}_{3}\right)$ Association, midline, intralaminar and motor thalamic nuclei. Photomicrographic images were taken from Vehicle/Control ( $A_{1}$ and $\left.B_{1}\right)$, Vehicle/Stress $\left(A_{2}\right.$ and $\left.B_{2}\right)$ and Diazepam/Stress $\left(A_{3}\right.$ and $\left.B_{3}\right)$ groups. For other abbreviations, see the abbreviation list. Scale bar: $500 \mu \mathrm{m}$. 

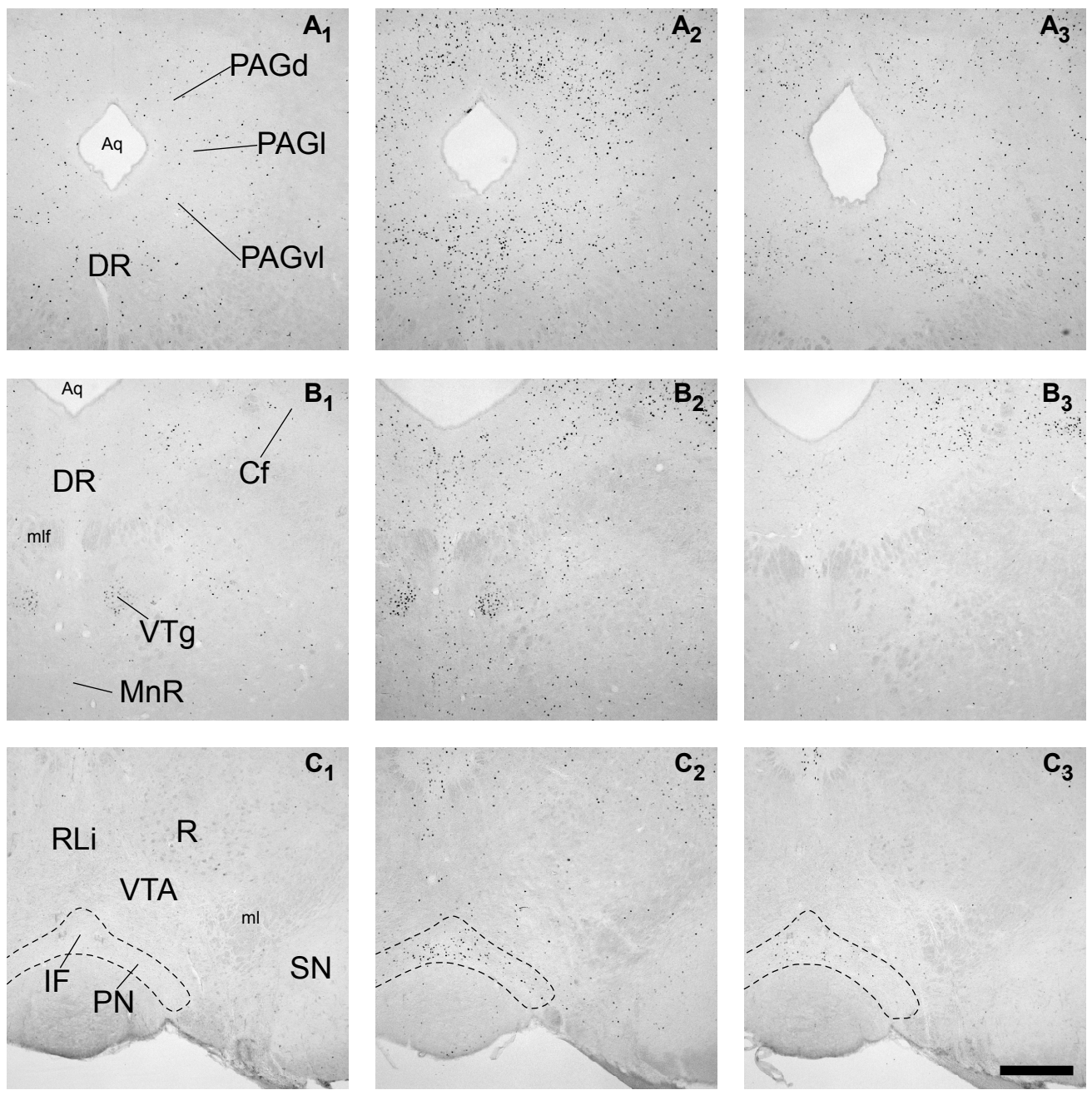

Lkhagvasuren et al., Neuroscience

Figure 9. Two column width

Fig. 9. Distribution of Fos-IR cells in the midbrain. $\left(A_{1}-A_{3}\right)$ Periaqueductal gray. $\left(B_{1}-B_{3}\right)$ Raphe nuclei. $\left(C_{1}-C_{3}\right)$ Nigrotegmental area. Broken lines delineate a zonal region consisting of the interfascicular nucleus (IF) and paranigral nucleus (PN). Photomicrographic images were taken from Vehicle/Control $\left(A_{1}-C_{1}\right)$, Vehicle/Stress $\left(A_{2}-C_{2}\right)$ and Diazepam/Stress $\left(A_{3}-C_{3}\right)$ groups. For other abbreviations, see the abbreviation list. Scale bar: $500 \mu \mathrm{m}$. 
Table 1. Density of Fos-IR cells in forebrain and midbrain regions after four experimental treatments

\begin{tabular}{|c|c|c|c|c|c|c|c|c|}
\hline \multirow{2}{*}{ Brain region } & \multirow{2}{*}{$\begin{array}{l}\text { Vehicle } \\
\text { /Control }\end{array}$} & \multirow{2}{*}{$\begin{array}{l}\text { Vehicle } \\
\text { IStress }\end{array}$} & \multirow{2}{*}{$\begin{array}{l}\text { Diazepam } \\
\text { /Stress }\end{array}$} & \multirow{2}{*}{ Type } & \multirow{2}{*}{$\begin{array}{l}\text { Diazepam } \\
\text { /Control }\end{array}$} & \multicolumn{3}{|c|}{ ANOVA } \\
\hline & & & & & & $\mathbf{S}$ & D & I \\
\hline \multicolumn{9}{|l|}{ Cerebral cortices } \\
\hline Orbital cortex & $16.1 \pm 2.0$ & $95.3 \pm 12.3, a^{* * *}$ & $25.2 \pm 7.8, \mathbf{d}^{\star * *}$ & 1 & $8.1 \pm 2.1$ & $* * *$ & $* * *$ & ** \\
\hline Frontal cortex & $4.3 \pm 2.5$ & $28.2 \pm 8.7, a^{*}$ & $5.5 \pm 2.7, \mathrm{~d}^{*}$ & 1 & $4.3 \pm 0.6$ & * & * & * \\
\hline Motor cortex & $9.8 \pm 1.2$ & $86.8 \pm 9.4, a^{\star * * *}$ & $26.8 \pm 2.7, \mathbf{d}^{* * *}$ & 1 & $5.6 \pm 0.9$ & $* * *$ & $* * *$ & $* * *$ \\
\hline \multicolumn{9}{|l|}{ Somatosensory cortex } \\
\hline Primary & $15.8 \pm 6.8$ & 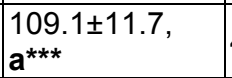 & $43.7 \pm 9.2, \mathbf{d}^{* * *}$ & 1 & $7.3 \pm 1.1$ & $* * *$ & $* * *$ & ** \\
\hline Secondary & $15.2 \pm 5.5$ & $89.3 \pm 4.4, \mathbf{a}^{\star \star *}$ & $40.4 \pm 11.4, \mathbf{d}^{\star *}$ & 1 & $12.7 \pm 2.2$ & $* * *$ & ** & ** \\
\hline Parietal cortex & $14.7 \pm 8.9$ & $\begin{array}{l}129.5 \pm 13.2 \\
a^{* * *}\end{array}$ & $\begin{array}{l}5.8 \pm 12.8, \\
\mathbf{d}^{* * *}\end{array}$ & 1 & $8.6 \pm 2.2$ & $* * *$ & $* * *$ & ** \\
\hline Visual cortex & $20.3 \pm 5.0$ & $151.8 \pm 4.2, \mathbf{a}^{* * *}$ & $97.5 \pm 8.8, \mathbf{d}^{* * *}$ & 1 & $10.4 \pm 1.6$ & $* * *$ & $* * *$ & ** \\
\hline Auditory cortex & $14.1 \pm 3.2$ & $\begin{array}{l}119.8 \pm 14.4 \\
a^{* * *}\end{array}$ & $43.3 \pm 6.6, \mathbf{d}^{* * *}$ & 1 & $9.8 \pm 1.8$ & $* * *$ & $* * *$ & $* * *$ \\
\hline Prelimbic cortex & $13.3 \pm 1.9$ & $92.5 \pm 5.9, \mathbf{a}^{* * *}$ & $17.5 \pm 1.5, \mathbf{d}^{* * *}$ & 1 & $13.1 \pm 2.3$ & $* * *$ & $* * *$ & $* * *$ \\
\hline Infralimbic cortex & $6.4 \pm 1.9$ & $67.0 \pm 7.5, \mathrm{a}^{\star \star * *}$ & $19.0 \pm 2.6, \mathbf{d}^{* * *}$ & 1 & $12.3 \pm 2.6$ & $* * *$ & $* * *$ & $* * *$ \\
\hline \multicolumn{9}{|l|}{ Cingulate cortex } \\
\hline Primary & $5.9 \pm 1.0$ & $87.7 \pm 2.3, \mathbf{a}^{\star \star *}$ & $33.5 \pm 7.7, \mathbf{d}^{* * *}$ & 1 & $4.3 \pm 0.4$ & $* \star \star *$ & $* * *$ & $* * *$ \\
\hline Secondary & $10.3 \pm 1.2$ & $76.4 \pm 4.1, a^{* \star *}$ & $15.8 \pm 4.0, \mathbf{d}^{* * *}$ & 1 & $3.9 \pm 0.6$ & $* * *$ & $* * *$ & $* * *$ \\
\hline Retrosplenial cortex & $11.0 \pm 4.0$ & $100.2 \pm 9.2, a^{* * *}$ & $16.3 \pm 4.0, \mathbf{d}^{* * *}$ & 1 & $3.8 \pm 1.0$ & $* * *$ & $* * *$ & $* * *$ \\
\hline Insular cortex & $10.6 \pm 1.0$ & $42.1 \pm 5.1, a^{* * *}$ & $16.7 \pm 5.3, \mathbf{d}^{* *}$ & 1 & $8.3 \pm 1.4$ & $* * *$ & ** & ** \\
\hline Ectorhinal and perirhinal cortices & $8.0 \pm 1.4$ & $72.7 \pm 11.7, a^{* * *}$ & $36.0 \pm 7.4, \mathbf{d}^{*}$ & 1 & $10.8 \pm 1.7$ & $* * *$ & * & * \\
\hline \multicolumn{9}{|l|}{ Piriform cortex } \\
\hline Layer II & $28.0 \pm 3.2$ & $\begin{array}{l}122.7 \pm 21.7 \\
a^{\star \star *}\end{array}$ & $51.3 \pm 8.2, \mathbf{d}^{\star *}$ & 1 & $16.3 \pm 2.1$ & $* * *$ & ** & * \\
\hline Layer III & $4.3 \pm 0.7$ & $12.1 \pm 1.3, \mathbf{a}^{*}$ & $6.3 \pm 2.1$ & 2 & $4.5 \pm 1.6$ & ** & NS & NS \\
\hline Anterior olfactory nucleus & $20.4 \pm 4.0$ & $67.2 \pm 6.9, \mathrm{a}^{* \star *}$ & $19.6 \pm 3.9, \mathbf{d}^{* * *}$ & 1 & $6.5 \pm 1.3$ & $* * *$ & $* * *$ & ** \\
\hline Entorhinal cortex & $5.4 \pm 2.2$ & $40.5 \pm 18.7$ & $12.7 \pm 1.6$ & 4 & $4.9 \pm 0.6$ & * & NS & NS \\
\hline \multicolumn{9}{|l|}{ Hippocampal formation } \\
\hline \multicolumn{9}{|l|}{ Ammon's horn } \\
\hline CA1 & $4.5 \pm 0.7$ & $35.1 \pm 5.4, a^{\star \star *}$ & $4.5 \pm 1.5, \mathrm{~d}^{* * *}$ & 1 & $0.9 \pm 0.5$ & $* * *$ & $* * *$ & $* * *$ \\
\hline CA3 & $4.3 \pm 1.5$ & $10.5 \pm 0.9, a^{*}$ & $3.4 \pm 1.2, \mathbf{d}^{* *}$ & 1 & $2.1 \pm 0.5$ & $* *$ & $* *$ & * \\
\hline Dentate gyrus & $9.4 \pm 2.0$ & $18.4 \pm 4.3$ & $4.8 \pm 0.3, \mathbf{d}^{*}$ & 4 & $3.6 \pm 1.2$ & NS & ** & NS \\
\hline Ventral subiculum & $7.2 \pm 1.7$ & $50.7 \pm 5.6, a^{* * *}$ & $9.8 \pm 3.3, \mathbf{d}^{* * *}$ & 1 & $3.8 \pm 1.3$ & $* * *$ & $* * *$ & $* * *$ \\
\hline \multicolumn{9}{|l|}{ Septal region } \\
\hline Lateral septal nucleus & $18.3 \pm 2.2$ & $58.7 \pm 5.2, a^{* * *}$ & $28.3 \pm 6.2, \mathbf{d}^{* *}$ & 1 & $6.1 \pm 0.7$ & $* * *$ & $* * *$ & NS \\
\hline Medial septal nucleus & $2.3 \pm 0.5$ & $8.3 \pm 1.5, \mathbf{a}^{*}$ & $2.6 \pm 1.3, \mathbf{d}^{*}$ & 1 & $4.5 \pm 1.0$ & NS & NS & ** \\
\hline Nucleus of the diagonal band & $10.2 \pm 1.3$ & $41.3 \pm 0.8, a^{* * *}$ & $14.7 \pm 3.7, \mathbf{d}^{* \star *}$ & 1 & $5.1 \pm 0.6$ & $* * *$ & $* * *$ & $* * *$ \\
\hline \multicolumn{9}{|l|}{ Bed nucleus of the stria terminalis } \\
\hline Dorsal divisions & $23.3 \pm 3.6$ & $42.2 \pm 3.6, \mathrm{a}^{*}$ & $31.8 \pm 2.1$ & 2 & $21.4 \pm 3.8$ & $* * *$ & NS & NS \\
\hline Ventral divisions & $18.1 \pm 2.6$ & $50.4 \pm 6.8, a^{* * *}$ & $19.5 \pm 2.4, \mathbf{d}^{* * *}$ & 1 & $10.3 \pm 1.3$ & $* * *$ & $* * *$ & * \\
\hline \multicolumn{9}{|l|}{ Basal ganglia } \\
\hline Caudate putamen & $0.9 \pm 0.3$ & $29.8 \pm 5.8, \mathbf{a}^{\star \star *}$ & $5.5 \pm 1.4, \mathbf{d}^{* * *}$ & 1 & $1.2 \pm 0.6$ & $* * *$ & ** & ** \\
\hline Accumbens nucleus & $28.4 \pm 6.0$ & $73.9 \pm 1.7, \mathbf{a}^{\star \star \star}$ & $19.3 \pm 4.3, \mathbf{d}^{* * *}$ & 1 & $17.0 \pm 3.2$ & $* * *$ & $* * *$ & $* * *$ \\
\hline
\end{tabular}




\begin{tabular}{|c|c|c|c|c|c|c|c|c|}
\hline \multirow{2}{*}{ Brain region } & \multirow{2}{*}{$\begin{array}{l}\text { Vehicle } \\
\text { /Control }\end{array}$} & \multirow{2}{*}{$\begin{array}{l}\text { Vehicle } \\
\text { /Stress }\end{array}$} & \multirow{2}{*}{$\begin{array}{l}\text { Diazepam } \\
\text { /Stress }\end{array}$} & \multirow{2}{*}{ Type } & \multirow{2}{*}{$\begin{array}{l}\text { Diazepam } \\
\text { /Control }\end{array}$} & \multicolumn{3}{|c|}{ ANOVA } \\
\hline & & & & & & $\mathbf{S}$ & D & I \\
\hline Globus pallidus & $0.5 \pm 0.5$ & $4.3 \pm 1.5, \mathbf{a}^{*}$ & $0.6 \pm 0.2, \mathbf{d}^{*}$ & 1 & $0.6 \pm 0.4$ & * & * & * \\
\hline Ventral pallidum & $6.8 \pm 1.6$ & $35.1 \pm 2.0, \mathbf{a}^{\star \star \star *}$ & $10.8 \pm 2.4, \mathbf{d}^{* \star \star}$ & 1 & $7.8 \pm 2.9$ & $* * *$ & $* * *$ & $* * *$ \\
\hline $\begin{array}{l}\text { Navicular nucleus of the basal } \\
\text { forebrain }\end{array}$ & $9.7 \pm 2.4$ & $40.7 \pm 2.0, a^{* * *}$ & $15.4 \pm 1.9, \mathbf{d}^{* * *}$ & 1 & $5.3 \pm 0.6$ & $* * *$ & $* * *$ & $* * *$ \\
\hline \multicolumn{9}{|l|}{ Endopiriform nucleus } \\
\hline Rostral part & $13.8 \pm 2.2$ & $58.3 \pm 6.2, a^{* * *}$ & $21.2 \pm 2.8, \mathbf{d}^{\star \star \star *}$ & 1 & $9.2 \pm 2.9$ & $* * *$ & $* * *$ & ** \\
\hline Caudal part & $10.9 \pm 1.3$ & $47.8 \pm 4.0, a^{\star \star *}$ & $15.2 \pm 3.3, \mathbf{d}^{* \star *}$ & 1 & $7.1 \pm 2.7$ & $* * *$ & $* * *$ & $* * *$ \\
\hline Claustrum & $22.4 \pm 4.0$ & $35.6 \pm 8.4$ & $18.9 \pm 1.6$ & 4 & $11.5 \pm 1.4$ & NS & * & NS \\
\hline \multicolumn{9}{|l|}{ Amygdala } \\
\hline Cortical amygdaloid nucleus & $12.7 \pm 1.6$ & $67.6 \pm 7.0, a^{* * *}$ & $27.0 \pm 2.1, \mathbf{d}^{* * *}$ & 1 & $5.1 \pm 1.3$ & $* * *$ & $* * *$ & $* * *$ \\
\hline \multicolumn{9}{|l|}{ Central amygdaloid nucleus } \\
\hline Rostral part & $39.2 \pm 4.8$ & $35.7 \pm 6.3$ & $48.8 \pm 4.4$ & 4 & $57.1 \pm 2.5$ & NS & ** & NS \\
\hline Caudal part & $41.5 \pm 8.4$ & $53.3 \pm 5.5$ & $76.7 \pm 3.8$ & 4 & $84.7 \pm 5.6, \mathbf{a}^{* *}$ & NS & $* * *$ & NS \\
\hline Medial amygdaloid nucleus & $9.0 \pm 0.3$ & $62.1 \pm 5.0, a^{* * *}$ & $21.1 \pm 1.6, \mathbf{d}^{* * *}$ & 1 & $4.4 \pm 0.8$ & $* * *$ & $* * *$ & $* * *$ \\
\hline Basolateral amygdaloid nucleus & $6.4 \pm 1.4$ & $17.8 \pm 4.9$ & $9.6 \pm 1.8$ & 4 & $5.8 \pm 0.7$ & * & NS & NS \\
\hline Lateral amygdaloid nucleus & $6.9 \pm 1.5$ & $41.4 \pm 1.7, a^{\star \star \star *}$ & $12.8 \pm 2.0, \mathbf{d}^{\star \star *}$ & 1 & $4.5 \pm 1.1$ & $* * *$ & *** & $* * *$ \\
\hline Basomedial amygdaloid nucleus & $3.4 \pm 0.4$ & $21.1 \pm 4.0, a^{\star * *}$ & $7.9 \pm 1.0, \mathbf{d}^{* *}$ & 1 & $3.7 \pm 0.8$ & $* \star * \star$ & ** & ** \\
\hline \multicolumn{9}{|l|}{ Preoptic area and hypothalamus } \\
\hline $\begin{array}{l}\text { Organum vasculosum lamina } \\
\text { terminalis }\end{array}$ & $34.6 \pm 4.2$ & $40.0 \pm 10.6$ & $34.6 \pm 1.5$ & 4 & $31.6 \pm 4.2$ & NS & NS & NS \\
\hline Median preoptic nucleus & $26.4 \pm 6.1$ & $40.9 \pm 4.2$ & $19.6 \pm 0.7, \mathbf{d}^{*}$ & 4 & $19.9 \pm 3.1$ & NS & ** & NS \\
\hline Medial preoptic area & $22.3 \pm 1.9$ & $65.3 \pm 6.7, a^{* * *}$ & $31.3 \pm 4.1, \mathbf{d}^{* * *}$ & 1 & $14.3 \pm 3.1$ & $* * *$ & *** & * \\
\hline Lateral preoptic area & $9.2 \pm 1.6$ & $41.8 \pm 6.0, a^{\star \star *}$ & $20.1 \pm 3.7, \mathbf{d}^{\star \star}$ & 1 & $7.5 \pm 0.7$ & $* * *$ & ** & * \\
\hline Septohypothalamic nucleus & $17.3 \pm 4.3$ & $93.0 \pm 12.7, \mathbf{a}^{* * *}$ & $24.0 \pm 4.3, \mathbf{d}^{* * *}$ & 1 & $13.9 \pm 2.6$ & $* * *$ & $* * *$ & $* * *$ \\
\hline Parastrial nucleus & $33.1 \pm 8.3$ & $62.7 \pm 6.1, \mathrm{a}^{*}$ & $26.9 \pm 2.8, \mathbf{d}^{* *}$ & 1 & $27.6 \pm 2.3$ & * & ** & * \\
\hline Ventromedial preoptic nucleus & $18.8 \pm 6.4$ & $33.9 \pm 9.9$ & $6.4 \pm 1.9$ & 4 & $12.8 \pm 3.8$ & NS & * & NS \\
\hline Ventrolateral preoptic nucleus & $12.5 \pm 2.8$ & $48.4 \pm 7.5, \mathrm{a}^{\star * *}$ & $27.5 \pm 3.4, \mathbf{d}^{*}$ & 1 & $9.8 \pm 2.0$ & $* * *$ & * & NS \\
\hline Anterior hypothalamic area & $31.7 \pm 4.6$ & $50.3 \pm 6.1, \mathrm{a}^{*}$ & $40.0 \pm 1.7$ & 2 & $20.7 \pm 2.2$ & $* * *$ & * & NS \\
\hline Suprachiasmatic nucleus & $144.1 \pm 21.5$ & $307.4 \pm 4.7, \mathbf{a}^{* * *}$ & $\begin{array}{l}115.6 \pm 0.7 \\
\mathbf{d}^{* * *}\end{array}$ & 1 & $116.1 \pm 1.1$ & $* * *$ & $* * *$ & $* * *$ \\
\hline Supraoptic nucleus & $40.5 \pm 0.2$ & $18.8 \pm 10.5$ & $16.2 \pm 0.4$ & 4 & $5.5 \pm 0.2, \mathbf{b}^{\star *}$ & NS & ** & ** \\
\hline $\begin{array}{l}\text { Periventricular hypothalamic } \\
\text { nucleus }\end{array}$ & $6.8 \pm 0.3$ & $37.8 \pm 7.6, \mathrm{a}^{\star \star *}$ & $12.3 \pm 0.7, \mathbf{d}^{* *}$ & 1 & $5.3 \pm 0.4$ & $* * *$ & $* *$ & ** \\
\hline \multicolumn{9}{|l|}{$\begin{array}{l}\text { Paraventricular hypothalamic } \\
\text { nucleus }\end{array}$} \\
\hline Lateral magnocellular part & $23.0 \pm 1.5$ & $99.1 \pm 17.1, \mathbf{a}^{* *}$ & $54.6 \pm 14.6$ & 2 & $35.5 \pm 10.1$ & $* *$ & NS & * \\
\hline Medial parvicellular part & $42.1 \pm 4.7$ & $121.4 \pm 4.9, \mathbf{a}^{* * *}$ & $52.3 \pm 7.1, \mathbf{d}^{* * *}$ & 1 & $42.5 \pm 9.3$ & $* * *$ & $* * *$ & $* * *$ \\
\hline Ventral part & $19.2 \pm 2.9$ & $63.2 \pm 4.9, a^{* \star *}$ & $27.5 \pm 2.4, \mathbf{d}^{\star \star *}$ & 1 & $18.8 \pm 3.3$ & $* * *$ & $* * *$ & $* * *$ \\
\hline \multicolumn{9}{|l|}{ Arcuate nucleus } \\
\hline Rostral part & $8.3 \pm 2.3$ & $40.9 \pm 4.4, a^{* \star *}$ & $13.2 \pm 3.1, \mathbf{d}^{\star * *}$ & 1 & $6.8 \pm 1.2$ & $* * *$ & $* * *$ & $* * *$ \\
\hline Caudal part & $10.9 \pm 1.7$ & $63.8 \pm 12.5, a^{* * *}$ & $12.1 \pm 3.3, \mathbf{d}^{* * *}$ & 1 & $3.9 \pm 1.4$ & *** & *** & ** \\
\hline Dorsal hypothalamic area & $12.6 \pm 0.9$ & $46.2 \pm 3.8, a^{* * *}$ & $22.0 \pm 5.9, \mathbf{d}^{* *}$ & 1 & $10.3 \pm 2.2$ & $* * *$ & ** & * \\
\hline $\begin{array}{l}\text { Dorsomedial hypothalamic } \\
\text { nucleus }\end{array}$ & $5.8 \pm 1.9$ & $27.3 \pm 1.5, a^{\star \star *}$ & $15.1 \pm 1.5, \mathbf{d}^{\star *}$ & 1 & $10.0 \pm 2.3$ & $* * *$ & * & $* * *$ \\
\hline $\begin{array}{l}\text { Ventromedial hypothalamic } \\
\text { nucleus }\end{array}$ & $10.2 \pm 0.2$ & $8.8 \pm 1.5$ & $21.8 \pm 4.0, c^{* *}$ & 4 & $1.4 \pm 0.2$ & $* * *$ & NS & $* * *$ \\
\hline Perifornical nucleus & $15.3 \pm 3.0$ & $47.9 \pm 5.8, a^{* * *}$ & $20.9 \pm 3.0, \mathbf{d}^{* *}$ & 1 & $13.0 \pm 3.1$ & $* * *$ & ** & ** \\
\hline $\begin{array}{l}\text { Magnocellular nucleus of the } \\
\text { lateral hypothalamus }\end{array}$ & $13.8 \pm 0.5$ & $16.1 \pm 0.6$ & $26.3 \pm 0.6, c^{* * *}$ & 4 & $\begin{array}{l}20.5 \pm 0.8 \\
\mathbf{a}^{* * *}\end{array}$ & $* * *$ & $* * *$ & * \\
\hline
\end{tabular}




\begin{tabular}{|c|c|c|c|c|c|c|c|c|}
\hline \multirow{2}{*}{ Brain region } & \multirow{2}{*}{$\begin{array}{l}\text { Vehicle } \\
\text { /Control }\end{array}$} & \multirow{2}{*}{$\begin{array}{l}\text { Vehicle } \\
\text { IStress }\end{array}$} & \multirow{2}{*}{$\begin{array}{l}\text { Diazepam } \\
\text { /Stress }\end{array}$} & \multirow{2}{*}{ Type } & \multirow{2}{*}{$\begin{array}{l}\text { Diazepam } \\
\text { /Control }\end{array}$} & \multicolumn{3}{|c|}{ ANOVA } \\
\hline & & & & & & $\mathbf{S}$ & D & I \\
\hline $\begin{array}{l}\text { Peduncular part of the lateral } \\
\text { hypothalamus }\end{array}$ & $6.8 \pm 0.5$ & $35.9 \pm 0.2, a^{* \star *}$ & $14.3 \pm 0.5, \mathbf{d}^{* \star *}$ & 1 & $6.8 \pm 0.2$ & $* * *$ & $* * *$ & $* * *$ \\
\hline Posterior hypothalamic area & $15.8 \pm 3.1$ & $39.4 \pm 0.4, a^{* * *}$ & $17.4 \pm 0.3, \mathbf{d}^{* * *}$ & 1 & $5.1 \pm 0.3, \mathbf{b}^{* *}$ & $* * *$ & $* * *$ & ** \\
\hline \multicolumn{9}{|l|}{ Premammillary nucleus } \\
\hline Dorsal part & $20.3 \pm 1.6$ & $72.5 \pm 9.1, \mathbf{a}^{* * *}$ & $34.8 \pm 4.5, \mathbf{d}^{* *}$ & 1 & $7.5 \pm 0.3$ & *** & $* * *$ & * \\
\hline Ventral part & $1.1 \pm 0.6$ & $\begin{array}{l}117.9 \pm 12.2 \\
a^{* * *}\end{array}$ & $49.0 \pm 2.7, \mathbf{d}^{* * *}$ & 1 & $1.5 \pm 0.2$ & $* * *$ & $* * *$ & $* * *$ \\
\hline Supramammillary nucleus & $17.2 \pm 0.3$ & $61.5 \pm 7.8, a^{* \star *}$ & $27.5 \pm 2.9, \mathbf{d}^{* * *}$ & 1 & $12.3 \pm 0.7$ & $* * *$ & $* * *$ & ** \\
\hline Medial mammillary nucleus & $5.1 \pm 1.0$ & $67.1 \pm 17.1, a^{* *}$ & $2.4 \pm 0.8, \mathbf{d}^{* *}$ & 1 & $1.9 \pm 0.4$ & ** & ** & ** \\
\hline Ventral tuberomammillary nucleus & $7.9 \pm 5.9$ & $47.6 \pm 4.7, a^{* * *}$ & $20.8 \pm 2.1, \mathbf{d}^{* *}$ & 1 & $6.9 \pm 0.1$ & $* * *$ & ** & ** \\
\hline \multicolumn{9}{|l|}{ Habenula } \\
\hline Medial habenular nucleus & $4.8 \pm 2.0$ & $16.2 \pm 2.2, a^{* *}$ & $29.1 \pm 1.2, \mathrm{c}^{* * *}$ & 3 & $\begin{array}{l}20.5 \pm 0.7 \\
a^{\star \star *}\end{array}$ & $* * *$ & $* * *$ & NS \\
\hline Lateral habenular nucleus & $4.0 \pm 1.4$ & $28.3 \pm 5.9, a^{* *}$ & $11.8 \pm 2.1, \mathbf{d}^{*}$ & 1 & $11.4 \pm 3.4$ & ** & NS & ** \\
\hline \multicolumn{9}{|l|}{ Thalamus } \\
\hline \multicolumn{9}{|l|}{ Association thalamic nuclei } \\
\hline Anterodorsal nucleus & $12.4 \pm 4.1$ & $48.9 \pm 5.2, a^{* * *}$ & $17.1 \pm 3.5, \mathbf{d}^{* * *}$ & 1 & $8.7 \pm 1.5$ & $* * *$ & $* * *$ & ** \\
\hline Anteromedial nucleus & $2.0 \pm 2.0$ & $32.3 \pm 2.2, \mathrm{a}^{\star \star *}$ & $12.8 \pm 2.3, \mathbf{d}^{\star * *}$ & 1 & $1.8 \pm 0.5$ & $* * *$ & $* * *$ & $* * *$ \\
\hline Anteroventral nucleus & $1.9 \pm 1.8$ & $35.2 \pm 7.7, a^{* * *}$ & $12.8 \pm 2.2, \mathbf{d}^{*}$ & 1 & $7.0 \pm 0.2$ & *** & NS & ** \\
\hline Mediodorsal nucleus & $0.0 \pm 0.0$ & $21.6 \pm 2.7, a^{* * *}$ & $9.5 \pm 3.3, \mathbf{d}^{*}$ & 1 & $0.0 \pm 0.0$ & $* * *$ & * & * \\
\hline Laterodorsal nucleus & $0.3 \pm 0.3$ & $36.3 \pm 3.6, \mathbf{a}^{* * *}$ & $6.2 \pm 2.7, \mathbf{d}^{* * *}$ & 1 & $3.8 \pm 2.2$ & $* * *$ & $* * *$ & $* * *$ \\
\hline Reticular nucleus & $0.0 \pm 0.0$ & $36.5 \pm 5.8, a^{* * *}$ & $0.8 \pm 0.6, \mathbf{d}^{* * *}$ & 1 & $0.0 \pm 0.0$ & $* * *$ & $* * *$ & $* * *$ \\
\hline Submedius nucleus & $1.8 \pm 1.4$ & $41.8 \pm 6.7, \mathrm{a}^{\star \star \star *}$ & $25.8 \pm 1.3, \mathbf{d}^{*}$ & 1 & $8.5 \pm 1.6$ & $* * *$ & NS & ** \\
\hline \multicolumn{9}{|l|}{$\begin{array}{l}\text { Midline and intralaminar thalamic } \\
\text { nuclei }\end{array}$} \\
\hline Central lateral nucleus & $3.0 \pm 1.0$ & $40.2 \pm 4.7, a^{* * *}$ & $14.9 \pm 3.9, \mathbf{d}^{* *}$ & 1 & $6.4 \pm 3.3$ & $* * *$ & ** & ** \\
\hline Central medial nucleus & $18.2 \pm 2.5$ & $64.0 \pm 5.3, \mathbf{a}^{\star \star *}$ & $36.9 \pm 3.3, \mathbf{d}^{* * *}$ & 1 & $24.2 \pm 1.4$ & $* * *$ & $* *$ & $* * *$ \\
\hline Intermediodorsal nucleus & $11.0 \pm 1.2$ & $50.6 \pm 7.4, a^{* * *}$ & $26.8 \pm 5.0, \mathbf{d}^{*}$ & 1 & $9.3 \pm 0.7$ & $* * *$ & * & * \\
\hline Paracentral nucleus & $9.8 \pm 2.6$ & $28.6 \pm 5.2, a^{*}$ & $21.3 \pm 1.7$ & 2 & $14.7 \pm 3.1$ & $* *$ & NS & NS \\
\hline Paratenial nucleus & $0.1 \pm 0.1$ & $25.7 \pm 6.8$ & $16.1 \pm 11.2$ & 4 & $3.5 \pm 2.0$ & * & NS & NS \\
\hline Paraventricular nucleus & $41.5 \pm 3.8$ & $76.8 \pm 6.0, a^{* *}$ & $45.7 \pm 4.6, \mathbf{d}^{* *}$ & 1 & $42.4 \pm 6.6$ & $* *$ & * & * \\
\hline Reuniens nucleus & $2.9 \pm 1.4$ & $32.0 \pm 8.3, a^{* *}$ & $23.6 \pm 4.0$ & 2 & $12.6 \pm 1.2$ & $* *$ & NS & NS \\
\hline Rhomboid nucleus & $19.1 \pm 4.0$ & $61.7 \pm 7.7, a^{* * *}$ & $24.6 \pm 4.7, \mathbf{d}^{* *}$ & 1 & $6.2 \pm 2.0$ & $* * *$ & $* * *$ & * \\
\hline \multicolumn{9}{|l|}{ Motor thalamic nuclei } \\
\hline Ventrolateral nucleus & $0.0 \pm 0.0$ & $15.8 \pm 8.5$ & $4.0 \pm 2.2$ & 4 & $0.0 \pm 0.0$ & * & NS & NS \\
\hline Ventral anterior nucleus & $0.0 \pm 0.0$ & $8.9 \pm 4.6$ & $2.2 \pm 1.1$ & 4 & $0.0 \pm 0.0$ & * & NS & NS \\
\hline Ventral medial nucleus & $1.3 \pm 0.0$ & $20.9 \pm 4.5, a^{* * *}$ & $8.4 \pm 1.5, \mathbf{d}^{*}$ & 1 & $0.7 \pm 0.4$ & $* * *$ & * & * \\
\hline \multicolumn{9}{|l|}{ Sensory thalamic nuclei } \\
\hline Lateral geniculate nucleus & $41.3 \pm 4.6$ & $51.8 \pm 2.4$ & $35.9 \pm 3.9$ & 4 & $42.9 \pm 4.8$ & NS & NS & NS \\
\hline Medial geniculate nucleus & $0.5 \pm 0.5$ & $42.1 \pm 2.1, \mathrm{a}^{* * *}$ & $36.0 \pm 7.9$ & 2 & $2.7 \pm 0.8$ & $* * *$ & NS & NS \\
\hline Posterior nucleus & $1.5 \pm 1.5$ & $25.5 \pm 7.8, a^{* *}$ & $5.2 \pm 2.2, \mathbf{d}^{*}$ & 1 & $0.0 \pm 0.0$ & $* *$ & * & * \\
\hline Ventral posterior complex & $1.0 \pm 1.0$ & $28.4 \pm 8.3, a^{* *}$ & $1.3 \pm 0.9, \mathbf{d}^{* *}$ & 1 & $0.0 \pm 0.0$ & $* *$ & $* *$ & ** \\
\hline Zona incerta & $8.8 \pm 1.8$ & $28.5 \pm 3.4, a^{\star \star *}$ & $7.4 \pm 1.2, \mathbf{d}^{\star \star *}$ & 1 & $5.7 \pm 0.6$ & $* * *$ & $* * *$ & $* * *$ \\
\hline \multicolumn{9}{|l|}{ Midbrain } \\
\hline Superior colliculus & $16.3 \pm 2.6$ & $54.3 \pm 2.9, \mathrm{a}^{* *}$ & $30.3 \pm 10.4$ & 2 & $8.4 \pm 1.3$ & $* * *$ & * & NS \\
\hline \multicolumn{9}{|l|}{ Periaqueductal gray } \\
\hline Dorsomedial and dorsolateral & $8.8 \pm 1.8$ & $31.9 \pm 5.8, a^{* *}$ & $21.2 \pm 2.4$ & 2 & $8.3 \pm 1.6$ & $* * *$ & NS & NS \\
\hline
\end{tabular}




\begin{tabular}{|c|c|c|c|c|c|c|c|c|}
\hline \multirow{2}{*}{ Brain region } & \multirow{2}{*}{$\begin{array}{l}\text { Vehicle } \\
\text { /Control }\end{array}$} & \multirow{2}{*}{$\begin{array}{l}\text { Vehicle } \\
\text { /Stress }\end{array}$} & \multirow{2}{*}{$\begin{array}{l}\text { Diazepam } \\
\text { /Stress }\end{array}$} & \multirow{2}{*}{ Type } & \multirow{2}{*}{$\begin{array}{c}\text { Diazepam } \\
\text { /Control }\end{array}$} & \multicolumn{3}{|c|}{ ANOVA } \\
\hline & & & & & & $\mathbf{S}$ & D & I \\
\hline parts & & & & & & & & \\
\hline Lateral part & $5.3 \pm 0.3$ & $14.7 \pm 0.8, a^{* \star *}$ & $10.2 \pm 0.3, \mathbf{d}^{* *}$ & 1 & $6.7 \pm 1.1$ & $* * *$ & NS & ** \\
\hline Ventrolateral part & $6.6 \pm 0.2$ & $20.9 \pm 3.7, a^{* \star}$ & $9.7 \pm 1.1, \mathbf{d}^{*}$ & 1 & $3.8 \pm 1.3$ & $* * *$ & ** & NS \\
\hline Retrorubral field & $6.4 \pm 1.0$ & $13.5 \pm 3.3$ & $5.9 \pm 0.8$ & 4 & $5.7 \pm 1.0$ & NS & * & NS \\
\hline Interfascicular nucleus & $3.6 \pm 0.9$ & $24.4 \pm 2.0, \mathbf{a}^{* * *}$ & $13.1 \pm 3.0, \mathbf{d}^{* *}$ & 1 & $4.4 \pm 0.8$ & $* * *$ & * & ** \\
\hline Paranigral nucleus & $1.1 \pm 0.3$ & $10.2 \pm 1.9, a^{* * *}$ & $3.3 \pm 0.1, \mathbf{d}^{* *}$ & 1 & $2.2 \pm 0.6$ & $* * *$ & * & $* *$ \\
\hline Ventral tegmental area & $1.2 \pm 0.3$ & $6.0 \pm 0.1, a^{* * *}$ & $1.5 \pm 0.3, \mathbf{d}^{* \star *}$ & 1 & $1.2 \pm 0.4$ & $* * *$ & $* * *$ & $* * *$ \\
\hline Substantia nigra & $0.0 \pm 0.0$ & $0.0 \pm 0.0$ & $0.0 \pm 0.0$ & 4 & $0.0 \pm 0.0$ & NS & NS & NS \\
\hline Red nucleus & $2.1 \pm 2.0$ & $1.0 \pm 0.6$ & $1.0 \pm 0.9$ & 4 & $0.8 \pm 0.8$ & NS & NS & NS \\
\hline Inferior colliculus & $34.3 \pm 6.9$ & $65.8 \pm 7.0$ & $44.3 \pm 7.3$ & 4 & $43.9 \pm 11.5$ & NS & NS & NS \\
\hline Cuneiform nucleus & $11.6 \pm 3.2$ & $48.9 \pm 4.6, a^{* * *}$ & $26.6 \pm 7.0, \mathbf{d}^{*}$ & 1 & $13.5 \pm 3.8$ & $* * *$ & NS & * \\
\hline Ventral tegmental nucleus & $17.0 \pm 5.6$ & $38.9 \pm 3.1, a^{* \star}$ & $9.1 \pm 1.8, \mathbf{d}^{\star \star \star}$ & 1 & $5.7 \pm 2.5$ & $* *$ & $* * *$ & * \\
\hline Linear nucleus of the raphe & $0.8 \pm 0.6$ & $10.4 \pm 2.2, \mathrm{a}^{*}$ & $5.9 \pm 3.0$ & 2 & $1.3 \pm 1.1$ & $* *$ & NS & NS \\
\hline Median raphe nucleus & $11.6 \pm 2.2$ & $29.3 \pm 4.7, a^{* *}$ & $6.2 \pm 0.8, \mathbf{d}^{* * *}$ & 1 & $4.1 \pm 1.1$ & $* *$ & $* * *$ & * \\
\hline Dorsal raphe nucleus & $9.3 \pm 1.6$ & $44.8 \pm 3.7, a^{* * *}$ & $22.3 \pm 1.0, \mathbf{d}^{* * *}$ & 1 & $10.3 \pm 2.9$ & $* * *$ & $* *$ & $* * *$ \\
\hline
\end{tabular}

Means \pm S.E.M. of densities of Fos-IR cells (cells $/ 0.04 \mathrm{~mm}^{2}$ ) are shown. In each brain region, statistical analyses of cell densities were performed using a two-way ANOVA (stress $x$ diazepam) to detect the effects of stress (S) and diazepam (D) and the interaction (I) of these factors $\left({ }^{* * *} P<0.001,{ }^{* *} P<0.01,{ }^{*} P<0.05\right.$; NS, not significant). Subsequently, a Bonferroni post hoc test was performed to compare 1) Vehicle/Control and Vehicle/Stress, 2) Vehicle/Stress and Diazepam/Stress, and 3) Vehicle/Control and Diazepam/Control, and the results are shown as follows: a, significantly increased from the Vehicle/Control group; b, significantly decreased from the Vehicle/Control group; c, significantly increased from the Vehicle/Stress group; d, significantly decreased from the Vehicle/Stress group $\left({ }^{* * *} P<0.001,{ }^{* *} P<0.01,{ }^{*} P<0.05\right)$. Based on the results from the comparisons 1) and 2), the brain regions were classified into four types: type 1, stress increased Fos expression, which was decreased by diazepam; type 2, stress increased Fos expression, which was not altered by diazepam; type 3, stress increased Fos expression, which was further increased by diazepam; and type 4, stress did not increase Fos expression. 
Table 2. Diazepam-caused reduction of stress-induced increase in FosIR cell density in type 1 regions

\begin{tabular}{|c|c|}
\hline Brain region & $\%$ reduction \\
\hline \multicolumn{2}{|l|}{ Cerebral Cortices } \\
\hline Orbital cortex & 88.5 \\
\hline Frontal cortex & 95.0 \\
\hline Motor cortex & 77.9 \\
\hline \multicolumn{2}{|l|}{ Somatosensory cortex } \\
\hline Primary & 70.1 \\
\hline Secondary & 66.0 \\
\hline Parietal cortex & 81.6 \\
\hline Visual cortex & 41.3 \\
\hline Auditory cortex & 72.4 \\
\hline Prelimbic cortex & 94.7 \\
\hline Infralimbic cortex & 79.2 \\
\hline \multicolumn{2}{|l|}{ Cingulate cortex } \\
\hline Primary & 66.3 \\
\hline Secondary & 91.7 \\
\hline Retrosplenial cortex & 94.1 \\
\hline Insular cortex & 80.6 \\
\hline Ectorhinal and perirhinal cortices & 56.7 \\
\hline Piriform cortex, layer II & 75.4 \\
\hline Anterior olfactory nucleus & 101.7 \\
\hline \multicolumn{2}{|l|}{ Hippocampal formation } \\
\hline \multicolumn{2}{|l|}{ Ammon's horn } \\
\hline CA1 & 100.0 \\
\hline CA3 & 114.5 \\
\hline Ventral subiculum & 94.0 \\
\hline \multicolumn{2}{|l|}{ Septal region } \\
\hline Lateral septal nucleus & 75.2 \\
\hline Medial septal nucleus & 95.0 \\
\hline Nucleus of the diagonal band & 85.5 \\
\hline Bed nucleus of the stria terminalis, ventral divisions & 95.7 \\
\hline \multicolumn{2}{|l|}{ Basal ganglia } \\
\hline Caudate putamen & 84.1 \\
\hline Accumbens nucleus & 120.0 \\
\hline Globus pallidus & 97.4 \\
\hline Ventral pallidum & 85.9 \\
\hline Navicular nucleus of the basal forebrain & 81.6 \\
\hline \multicolumn{2}{|l|}{ Endopiriform nucleus } \\
\hline Rostral part & 83.4 \\
\hline Caudal part & 88.3 \\
\hline \multicolumn{2}{|l|}{ Amygdala } \\
\hline Cortical amygdaloid nucleus & 74.0 \\
\hline Medial amygdaloid nucleus & 77.2 \\
\hline
\end{tabular}




\begin{tabular}{|c|c|}
\hline Brain region & $\%$ reduction \\
\hline Lateral amygdaloid nucleus & 82.9 \\
\hline Basomedial amygdaloid nucleus & 74.6 \\
\hline \multicolumn{2}{|l|}{ Preoptic area and hypothalamus } \\
\hline Medial preoptic area & 79.1 \\
\hline Lateral preoptic area & 66.6 \\
\hline Septohypothalamic nucleus & 91.1 \\
\hline Parastrial nucleus & 120.9 \\
\hline Ventrolateral preoptic nucleus & 58.2 \\
\hline Suprachiasmatic nucleus & 117.5 \\
\hline Periventricular hypothalamic nucleus & 82.3 \\
\hline \multicolumn{2}{|l|}{ Paraventricular hypothalamic nucleus } \\
\hline Medial parvicellular part & 87.1 \\
\hline Ventral part & 81.1 \\
\hline \multicolumn{2}{|l|}{ Arcuate nucleus } \\
\hline Rostral part & 85.0 \\
\hline Caudal part & 97.7 \\
\hline Dorsal hypothalamic area & 72.0 \\
\hline Dorsomedial hypothalamic nucleus & 56.7 \\
\hline Perifornical nucleus & 82.8 \\
\hline Peduncular part of the lateral hypothalamus & 74.2 \\
\hline Posterior hypothalamic area & 93.2 \\
\hline \multicolumn{2}{|l|}{ Premammillary nucleus } \\
\hline Dorsal part & 72.2 \\
\hline Ventral part & 59.0 \\
\hline Supramammillary nucleus & 76.7 \\
\hline Medial mammillary nucleus & 104.4 \\
\hline Ventral tuberomammillary nucleus & 67.5 \\
\hline \multicolumn{2}{|l|}{ Habenula } \\
\hline Lateral habenular nucleus & 67.9 \\
\hline \multicolumn{2}{|l|}{ Thalamus } \\
\hline \multicolumn{2}{|l|}{ Association thalamic nuclei } \\
\hline Anterodorsal nucleus & 87.1 \\
\hline Anteromedial nucleus & 64.4 \\
\hline Anteroventral nucleus & 67.3 \\
\hline Mediodorsal nucleus & 56.0 \\
\hline Laterodorsal nucleus & 83.6 \\
\hline Reticular nucleus & 97.8 \\
\hline Submedius nucleus & 40.0 \\
\hline \multicolumn{2}{|l|}{ Midline and intralaminar thalamic nuclei } \\
\hline Central lateral nucleus & 68.0 \\
\hline Central medial nucleus & 59.2 \\
\hline Intermediodorsal nucleus & 60.1 \\
\hline Paraventricular nucleus & 88.1 \\
\hline Rhomboid nucleus & 87.1 \\
\hline Motor thalamic nuclei & \\
\hline
\end{tabular}




\begin{tabular}{|l|c|}
\hline \multicolumn{1}{|c|}{ Brain region } & \% reduction \\
\hline Ventral medial nucleus & 63.8 \\
\hline Sensory thalamic nuclei & \\
\hline Posterior nucleus & 84.6 \\
\hline Ventral posterior complex & 98.9 \\
\hline Zona incerta & 107.1 \\
\hline Midbrain & \\
\hline Periaqueductal gray & \\
\hline Lateral part & 47.9 \\
\hline Ventrolateral part & 78.3 \\
\hline Interfascicular nucleus & 54.3 \\
\hline Paranigral nucleus & 75.8 \\
\hline Ventral tegmental area & 93.8 \\
\hline Cuneiform nucleus & 59.8 \\
\hline Ventral tegmental nucleus & 136.1 \\
\hline Median raphe nucleus & 130.5 \\
\hline Dorsal raphe nucleus & 63.4 \\
\hline
\end{tabular}

Inhibition \% of stress-induced increase in the density of Fos-IR cells in type 1 regions is listed. In each region, the mean basal density of Fos-IR cells in the Vehicle/Control group was subtracted from the mean densities in the Vehicle/Stress and Diazepam/Stress groups (see Table 1) to obtain stress-induced changes in FosIR cell density following vehicle and diazepam injections, respectively. Then, the reduction of the stress-induced increase in Fos-IR cell density by diazepam injection was expressed in \% of the stress-induced increase in Fos-IR cell density following vehicle injection. 